\title{
Purchasing Managers' Willingness to Pay for Attributes that Constitute Sustainability
}

\author{
Goebel, Philipp; Reuter, Carsten; Pibernik, Richard; Sichtmann, Christina; Bals, Lydia
}

\author{
Document Version \\ Accepted author manuscript \\ Published in: \\ Journal of Operations Management
}

DOI:

10.1016/j.jom.2018.08.002

Publication date:

2018

License

Unspecified

Citation for published version (APA):

Goebel, P., Reuter, C., Pibernik, R., Sichtmann, C., \& Bals, L. (2018). Purchasing Managers' Willingness to Pay for Attributes that Constitute Sustainability. Journal of Operations Management, 62, 44-58.

https://doi.org/10.1016/j.jom.2018.08.002

Link to publication in CBS Research Portal

\section{General rights}

Copyright and moral rights for the publications made accessible in the public portal are retained by the authors and/or other copyright owners and it is a condition of accessing publications that users recognise and abide by the legal requirements associated with these rights.

\section{Take down policy}

If you believe that this document breaches copyright please contact us (research.lib@cbs.dk) providing details, and we will remove access to the work immediately and investigate your claim. 


\title{
Purchasing Managers' Willingness to Pay for Attributes that Constitute Sustainability
}

\section{Philipp Goebel, Carsten Reuter, Richard Pibernik, Christina Sichtmann, and Lydia Bals}

\author{
Journal article (Accepted manuscript*)
}

\section{Please cite this article as:}

Goebel, P., Reuter, C., Pibernik, R., Sichtmann, C., \& Bals, L. (2018). Purchasing Managers' Willingness to Pay for Attributes that Constitute Sustainability. Journal of Operations Management, 62, 44-58. 001:

\subsection{6/j.jom.2018.08.002}

This is the peer reviewed version of the article, which has been published in final form at DOl:

https://doi.org/10.1016/j.jom.2018.08.002

This article may be used for non-commercial purposes in accordance with Wiley Terms and Conditions for SelfArchiving

* This version of the article has been accepted for publication and undergone full peer review but has not been through the copyediting, typesetting, pagination and proofreading process, which may

lead to differences between this version and the publisher's final version AKA Version of Record. 


\title{
Purchasing Managers' Willingness to Pay for Attributes that Constitute
}

\author{
Sustainability
}

Please cite as:

Göbel, Philipp/Reuter, Carsten/Pibernik, Richard/Sichtmann, Christina/Bals, Lydia

(forthcoming): Purchasing Managers' Willingness to Pay (WTP) for Attributes that Constitute

Sustainability, accepted at Journal of Operations Management.

The final version is available at: https://doi.org/10.1016/j.jom.2018.08.002

\begin{abstract}
Considering the increasing international division of labor, as well as stakeholders' growing awareness of sustainability, assuring that business practices are sustainable is a major challenge. Companies have to account for the fact that any misconduct at a supplier's premises may have spillover effects that reach the manufacturer or retailer. Therefore, purchasing managers have to assure that their suppliers are compliant with sustainability standards. This, however, may induce higher purchasing costs and, as a consequence, force a trade-off between (short term) economic (i.e., purchasing cost reduction) and social/environmental sustainability criteria. How purchasing managers evaluate this trade-off is particularly interesting because they often receive performance-based salaries that incentivize the reduction of purchasing costs. Our paper sheds light on this trade-off by examining how much purchasing managers are willing to pay to assure compliance along different sustainability dimensions when selecting new suppliers in a mature market setting, namely Germany. Additionally, we identify potential (individual, professional, and organization-related) factors that may impact the purchasing managers' willingness to pay (WTP), and examine their effects. Among the most surprising findings, purchasing managers on average are willing to pay a price premium for manuals that demonstrate compliance with the United Nationals Global Compact (UNGC). Furthermore, the results show that this WTP is mostly influenced (negatively) by self-enhancement (on the individual level) and/or obedience to authority (on the organizational level), but the effects of company, affiliation with the UNGC, gender, or years of experience have no influence. Moreover, the WTP is higher for the social than for the environmental dimension, and the marginal effect of accreditation on WTP depends on which combinations of dimensions are accredited.
\end{abstract}

Keywords: Willingness to Pay, Industrial Purchasing, Supply Management, Sustainability, Triple Bottom Line, Obedience to Authority, Sustainable Sourcing 
Accepted version status August 20, 2018

\section{Introduction}

Sustainability has emerged as an increasingly important topic for both practitioners and academics (Boyd et al., 2007; Johnsen et al., 2017; Walker and Phillips, 2009). In general terms, sustainability refers to a balance between social, environmental, and economic criteria in business (Montiel, 2008). Very often, these three dimensions are also reflected in what has been termed the "triple bottom line" (TBL) (Elkington, 1998). Werbach (2009, p. 111) contributes to this understanding specifying that the TBL emphasizes not only traditional measures of accounting that can be attributed to the economic dimension, but also the measurement of environmental and social performance. Companies face major challenges if they seriously pursue a TBL-approach to doing business: very often, increasing performance in one dimension comes at the cost of diminishing returns in another. More specifically, companies often face a trade-off between achieving (short-term) economic performance and performance in the social and environmental dimensions (Hahn et al., 2010, 2017).

In Purchasing and Supply Management (PSM), this trade-off between the different dimensions of sustainability is particularly relevant. Decision makers in PSM organizations (i.e., purchasing managers) often face situations in which short term economic objectives (e.g., purchasing certain goods at the lowest possible price) are in conflict with social and environmental criteria. In this context, previous research has suggested studying individual managers and employees; in other words, those who actually have to take and/or implement such decisions (Walker et al., 2014).

Moreover, one important feature makes sustainability considerations unique in a PSM context: the requirement to conduct business in a sustainable manner is not restricted to the immediate sphere of influence of a company, but is also extended to its upstream partners in 
Accepted version status August 20, 2018

the supply chain. Considering that up to $60-80 \%$ of the total costs of a modern firm are directly with suppliers (Monczka et al., 2016; van Weele, 2009; van Weele and van Raaij, 2014), the upstream network plays a paramount role in the delivery of companies' products and services. Organizations face enhanced scrutiny by a diverse range of stakeholders, such as governments and powerful non-governmental organizations (NGOs), to ensure that internationally accepted social and environmental standards are also met by their suppliers (Gualandris et al., 2015; Haddock-Fraser and Tourelle, 2010; Reuter et al., 2012); otherwise, they risk their economic performance (Reuter et al., 2010).

Due to its position at the foremost frontier to suppliers, as well as the increasing volume of purchased goods and services relative to an organizations' total expenditure, PSM has emerged as an important function in safeguarding organizations from being exposed to negative consequences resulting from unsustainable behavior on the part of their suppliers (Carter and Jennings, 2004; Foerstl et al., 2015; Handfield et al., 2002). The well-known example of Nike illustrates both the trade-off between sustainability dimensions as well as the extended responsibility for sustainable behavior: Nike was primarily held responsible for sourcing products (presumably at a lower cost) from a supplier who employed children at its premises (Zadek, 2004). Other prominent examples like Mattel (Eckert, 2007) and BP (Hayward, 2010) provide further anecdotal evidence for the important role of PSM in ensuring sustainability.

In this paper, we focus on sustainability within the critical buyer-supplier dyad. Consider, for example, a manufacturer of consumer goods. If, as argued previously, the concept of sustainability spans beyond the company's organizational boundaries, assuring responsible behavior on the supplier's side should be a decisive factor in the manufacturer's choice of suppliers and the design of supply contracts. The suppliers, in return, should react to these requirements by assuring certain levels of compliance with different sustainability dimensions. 
Accepted version status August 20, 2018

Suppliers can decide to comply with different sustainability standards such as the UN Global Compact or the GRI Guidelines as a means of credibly demonstrating their sustainable behavior and commitments. The UN Global Compact, for example, distinguishes between four different sustainability dimensions (i.e., human rights, labor, environment, and anti-corruption). Additionally, suppliers may choose between different practices and measures to provide their customers with evidence for being compliant with these sustainability standards. The most basic level of assurance is a contractual clause, e.g., stating that a supplier complies with certain social or environmental standards. Still, enforcing contracts is a difficult task around the world (Bank, 2009). Buying companies are always confronted with the risk that suppliers behave in an opportunistic way (Williamson, 1975), which may lead to financial losses for the buyer (March and Shapira, 1987). In the context of sustainability, these losses may occur especially as a result of damage to the buying company's brand and the related negative impacts on its image (Basu and Palazzo, 2008) caused by breaches of sustainability standards on the supplier's side. As a more credible measure to limit negative externalities, a buying company may require that a supplier furnishes certificates from independent agencies to provide evidence for compliance with sustainability principles, or allows unannounced on-site visits (van Tulder and van der Zwart, 2006). We refer to this as accreditation in the following research. This may lower the buying company's risks of incurring costs associated with the supplier's opportunistic behavior and, because of the lowered risk, lower the total transaction costs related to the purchase. Effective measures to reduce the risk of the buying company (e.g., accreditation), however, require significant investments on the supplier's side (Houston and Johnson, 2000). To determine the right set of measures for demonstrating compliance with sustainability standards, suppliers need to understand whether and how their customers (i.e., the buying companies) value such efforts. In this context, we have to recognize that a buying company 
Accepted version status August 20, 2018

mainly delegates the decision of which supplier to source from to individual purchasing managers (who act as agents on behalf of the buying company). Therefore, the following specific research question arises: Are purchasing managers (of buying companies) willing to pay a price premium to assure compliance with sustainability standards?

Two lines of reasoning central to this paper lead to different answers for the question of whether or not purchasing managers are willing to pay a positive price premium to assure that their suppliers comply with sustainability standards:

(1) Purchasing managers typically face a dilemma: they are most commonly incentivized to seek the lowest purchasing price while ensuring certain product specifications and quality standards (Goebel et al., 2012). Very often, they receive performance-based salaries that are tied to some measure of purchasing cost savings. On the contrary, suppliers who provide extensive evidence for being compliant with sustainability standards may want to charge a price premium and, therefore, may not provide purchasing cost savings. Ensuring sustainable behavior on the supplier's side may therefore be in conflict with a purchasing manager's traditional set of objectives. In many studies, the relationship between the social and environmental criteria and "the basic prerequisite of economic performance in sourcing is not explicitly specified" (Schneider and Wallenburg, 2012). Purchasing managers may perceive “difficulty of balancing the need to satisfy stakeholders' short term profit goals for longer term sustainability goals" and believe that sustainability might first require investments before payoffs are to be expected (Giunipero et al., 2012). Following this argument, a purchasing manager who is predominantly oriented towards cost savings will not be willing to pay a price premium to ensure sustainable behavior for a comparable product.

(2) Another line of reasoning can be derived from Transaction Cost Economics (TCE). Houston and Johnson (2000, p. 1) state that "firms select the lowest-cost transaction structures 
Accepted version status August 20, 2018

that effectively protect against partner opportunism [...], ensure their partners fulfil contractual obligations, and provide a framework for dealing with uncertainties." Both partner opportunism and dealing with uncertainties are important aspects in the context of suppliers' compliance with sustainability standards. On the one hand, as highlighted previously, the buyer faces the risk of substantial negative consequences from non-compliant behavior of its suppliers; on the other hand, the buyer incurs costs for monitoring supplier compliance and for protecting against suppliers' opportunistic behavior. Credible measures for supplier compliance (e.g. an internationally acknowledged accreditation) are likely to reduce these components of transaction costs. Consequently, from a firm perspective, a purchasing manager who acts on behalf of the company (i.e. as an agent) should be willing to pay a price premium for measures that assure supplier compliance corresponding to the perceived reduction in transaction costs. Additionally, we can also argue that a purchasing manager always faces the risk that certain selected suppliers will fail to comply with sustainability standards, leading to substantial negative personal consequences. Thus, a purchasing manager may relinquish economic incentives to achieve savings targets in order to secure his/her job by paying a price premium to assure that the selected supplier complies with sustainability standards.

Existing studies in the context of measuring willingness-to-pay (WTP) for sustainability focused on the price premium consumers are willing to pay if certain sustainability attributes are attached to a product. These studies, however, only focused on Business-to-Consumer (B2C) relationships and were predominantly limited to one specific sustainability dimension (Auger et al., 2008; De Pelsmacker et al., 2005a; McClenachan et al., 2016). So far, WTP research in supply chain and operations research has been mostly focused on consumers (e.g. Abbey et al., 2015; Shang et al., 2017). 
Accepted version status August 20, 2018

The results of these studies cannot be readily transferred to a Business-to-Business (B2B) context because purchasing decisions taken by purchasing managers may entail different consequences. They are also likely to be driven by a different set of objectives as compared to those taken by consumers of a specific product (Jackson et al., 1995; Stock and Zinszer, 1987). A consumer, for example, may not suffer any immediate consequences from non-compliant behavior by one or more parties in the supply chain, while, as outlined previously, purchasing managers may want to consider the potential negative effects for their own company when selecting suppliers and procuring products.

In spite of the specific characteristics of a B2B relationship, so far very little is known about WTP for sustainability in an industrial purchasing context versus the aforementioned consumer purchasing context. There are yet no prior studies that examine the price premium purchasing managers are willing to pay for different dimensions of sustainability to protect themselves from the risk of non-compliant supplier behavior. This motivates the first part of the analysis presented in this paper: we are interested in whether purchasing managers are willing to pay a price premium to assure that their suppliers are compliant with sustainability standards. To determine the WTP for assurance of compliance with certain sustainability standards and the factors that influence the WTP, we conducted an empirical analysis with 59 purchasing managers from multi-national companies located in Germany operating in different industry sectors. Thus, our study provides insights on purchasing managers' attitudes in a mature market setting.

Assuming that at least some purchasing managers exhibit willingness to pay a positive price premium (e.g., to reduce the transactions costs), we are also interested in the drivers and characteristics that influence this willingness. Shafer et al. (2007) show that individual values (e.g., self-transcendence values) influence decision-making with respect to social and 
Accepted version status August 20, 2018

environmental accountability. In a B2C context, Auger et al. (2008) found that some demographic variables have an influence on the value customers place on social product features. On an organizational level, literature provides evidence that ethical culture influences the extent to which ethical or unethical decisions are taken (Treviño et al., 1998). Previous research has also suggested that on an individual level, both "buyers and suppliers identify the same sets of activities as being unethical" (Carter, 2000a). The question then arises whether individual, professional, or organization-related characteristics also influence WTP to assure certain sustainability standards. This is especially relevant from a managerial perspective: knowing the drivers of the WTP for sustainability allows companies to develop certain measures to enhance sustainable decision-making in PSM organizations.

Investigations about corporate sustainable behavior may be subject to demand effects, i.e. "changes in behavior by experimental subjects due to cues about what constitutes appropriate behavior (behavior 'demanded' from them)" (Zizzo, 2010). This study aims to limit such demand effects in several ways. Building upon the different sustainability dimensions specified by the UN Global Compact (UNGC), we conducted a choice-based conjoint analysis to measure the price premium individual purchasing managers are willing to pay. Conjoint analysis is an implicit, indirect measurement approach where buyers have to make demanding trade-offs and concessions between different attributes of stimuli. Instead of specifying explicit priorities with respect to WTP for sustainability, respondents evaluate stimuli that present combinations of various attributes. The literature argues that this indirect measurement more realistically models buyer decisions and has a reasonable ability to predict behavior, particularly in a decision context where several purchasing attributes are involved (e.g., Green and Srinivasan, 1978). 
Accepted version status August 20, 2018

More specifically, it relates to the dilemma purchasing managers face when balancing profit and sustainability goals. As such, it is recommended as a method to limit social desirability biases in connection with sustainability questions (e.g., De Pelsmacker et al. (2005b); Kalafatis et al. (1999)) because the trade-off of product attributes makes it more difficult for respondents to "not respond truthfully but simply provide answers that make them look good" (Steenkamp et al., 2010). Second, we took several other steps to limit demand effects in our study such as conducting the study in a country context that is less prone to social desirability biases (Germany), conducting thorough pretests, obfuscating the study purpose without using deception and limiting interviewer bias.

Methodologically, we used the results of the choice-based analysis to estimate the willingness-to-pay (WTP). In a second step, we included the WTP in a binary logistics regression analysis to determine the influence of individual, professional, and organizationrelated characteristics.

The remainder of this paper is organized as follows: in the next section, we provide a short overview of studies examining sustainability, the dimensions of the UNGC, and the link between sustainability and WTP. Thereafter, we outline our research methodology, sampling procedure, and analytical techniques. In section 4, we present the results of our analysis and provide a detailed discussion of their implications. Finally, we highlight managerial implications and outline limitations, as well as future research opportunities.

\section{Literature Review}

The research presented in this paper is related to three streams of research: research on sustainability in PSM, the measurement of WTP for sustainability, and characteristics that may 
Accepted version status August 20, 2018

influence WTP. In the following sections, we provide a brief review of these areas and identify the research gap that motivates our research.

\subsection{Sustainability and the Purchasing Function}

Scholars have long acknowledged that supplier performance is to a large extent responsible for the quality, cost, and margin of products and services that buying firms offer in the market place, especially as a result of increasing outsourcing levels (Tsoulfas and Pappis, 2006). A buying firm's dependence on its suppliers' performance has been extended into the topic of sustainability. Carter and Rogers (2008) state that the growing influence of sustainability concerns on corporate strategies requires the PSM function to address the social, environmental, and economic dimensions of sustainability. As such, they draw special attention to the link between TCE (i.e., determined by the risk of non-compliant supplier behavior) and sustainability. They refer to "the ability of a firm to understand and manage its economic, environmental, and social risks in the supply chain" (Carter and Rogers, 2008). According to Werbach (2009, p. 111), "through this perspective, environmental and social costs are measured alongside purely financial gauges." The dimensions of the so called triple bottom-line (Elkington, 1998), however, have so far received imbalanced investigation in the purchasing literature. While the majority of contributions focus on environmental issues using different terms like 'green supply,' 'green purchasing,' or 'environmental purchasing' (Caniato et al., 2012; Carter and Carter, 1998; Côté et al., 2008; Grandia et al., 2015; Hall, 2000; Hsu and Hu, 2009; Kovács, 2008; Miemczyk et al., 2012; Mintcheva, 2005; Zhu et al., 2008), only a few focus on social issues under the umbrella of 'ethical sourcing' or 'purchasing social responsibility' (Carter, 2005; Carter and Jennings, 2004; Hutchins and Sutherland, 2008; Roberts, 2003). Integrating environmental and social issues in the fields of supply chain 
Accepted version status August 20, 2018

management and PSM has recently received growing attention (Boyd et al., 2007; Carter and Rogers, 2008; Linton et al., 2007; Seuring and Müller, 2008; Wu and Pagell, 2011), highlighting the potential benefits of a combined approach (e.g. Bals and Tate, 2018; Beske et al., 2008; Carter and Rogers, 2008; Matos and Hall, 2007; Montabon et al., 2016; Pagell and Wu, 2009; Yawar and Seuring, 2015). Boyd et al. (2007) focus on the impact of monitoring levels along social and environmental dimensions. They argue that higher monitoring levels will not necessarily increase supplier compliance, although the information asymmetry between buyer and supplier will be decreased. Instead, close monitoring may even damage buyersupplier relationships. It can signal distrust on the part of the monitoring party, wherein a common reaction by the distrusted party is to engage in retaliatory behavior such as noncompliance. Linton et al. (2007) provide a comprehensive overview on sustainability issues in supply chains. They acknowledge that both natural sciences and social sciences need to be considered in the discussion of supply chain sustainability. In their extensive literature review, Seuring and Müller (2008, p. 1706) conclude that "an integrated perspective is required for future research where social issues in particular and the interrelation of the three dimensions need to be investigated much further." Moreover, they state that "the quest for reaching the performance frontier has to include the environmental and social dimension as well, taking the trade-off debate to a further, broader level." Although these authors mention a trade-off situation between the three dimensions of sustainability, with additional costs supposedly being a major barrier to sustainable actions, none of the studies actually explores whether or not purchasing managers are willing to pay a premium for compliance with sustainability standards. 
Accepted version status August 20, 2018

\subsection{Willingness to Pay for Sustainability}

Existing studies on WTP for sustainability have so far only been carried out in a B2C context (Auger et al., 2008; Elliot and Freeman, 2001; McGoldrick and Freestone, 2008). The research presented in this paper intends to close this research gap by measuring WTP for assuring sustainability in purchasing. Most of them focused on hedonic products such as chocolate or coffee (Arnot et al., 2006; De Pelsmacker et al., 2005a; Didier and Lucie, 2008; Loureiro and Lotade, 2005). While Arnot et al. (2006) found that "purchasers of fair trade coffee were much less price responsive than those of other coffee products," De Pelsmacker et al. (2005a) found that "consumers' buying behavior is not consistent with their positive attitude toward ethical products" when considering the characteristics of each individual.

The focus of previous studies has been on three sustainability dimensions: (1) human rights, (2) labor, and (3) the environment. Two studies stand out having examined all three of these dimensions simultaneously. Didier and Lucie (2008) applied a BDM (Becker-DeGrootMarschak) lottery to estimate the WTP of consumers for chocolate with an organic and fair trade label. Loureiro and Lotade (2005) estimated WTP for fair trade, organic, and shaded coffee, applying a contingent valuation approach. Products with a fair trade label can be seen as being produced under the protection of human rights and labor standards according to the Fair Trade Organization (FLO, 2010). The organic label can be seen as a representative for the environmental dimension. De Pelsmacker et al. (2005a) examined WTP for fair trade coffee; however, they did not concentrate on the environmental dimension. In contrast, Auger et al. (2003), and Auger et al. (2008), focus on the environmental and labor dimensions, applying a choice experiment to determine the WTP for different products. To the best of our knowledge, the majority of other studies focused only on the environmental dimension (Arnot et al., 2006; 
Accepted version status August 20, 2018

Elliot and Freeman, 2001), but there are some prior studies that estimated ethical price premiums in more general terms (e.g., McGoldrick and Freestone, 2008).

The results of these studies reveal large differences in price premiums. While Didier and Lucie (2008) found a relatively low additional WTP of 2.4-3.3\% for organic and fair trade labelled chocolate products, Loureiro and Lotade (2005) found a wide range of $4.9-48.1 \%$ for ethical and environmentally sound labelling programs with respect to coffee. Elliot and Freeman (2001) found that consumers would pay an ethical price premium of $28 \%$ for an item worth $\$ 10$, while the price premium for an item worth $\$ 100$ would only be $15 \%$. Based on this discussion, we conclude that previous research on WTP for sustainability in B2C contexts does not contribute to answering the research questions stated in section 1 . The results obtained from earlier studies are neither suitable for assessing the price premium a purchasing manager is willing to pay for assuring sustainability, nor do they provide insights and guidance on how to influence them. Different arguments provide support for this reasoning: first, the estimates for price premiums are largely varied, so a consistent pattern cannot be detected. Accordingly, retrieving a specific range of price premiums purchasing managers could be provided with when estimating their willingness to pay is difficult. Second, consumers do not face the risk of negative consequences when purchasing non-sustainable products. In contrast, purchasing managers may risk their job when sourcing from non-sustainable suppliers. Finally, incentives for buying sustainable products differ between consumers and purchasing managers. While consumers may purchase a sustainable product due to their internal beliefs, purchasing managers often receive economic incentives. This motivates the analysis presented in the remainder of our paper. 
Accepted version status August 20, 2018

\subsection{Individual Values and Characteristics Influencing Willingness to Pay}

\section{Individual Values of Employees}

Because we are also interested in the factors that may influence WTP, not just purchasing managers' WTP, we briefly discuss individual values and characteristics that may have an influence on the purchasing managers' WTP. Individual values are defined as "an enduring belief that a specific mode of conduct or end-state of existence is personally or socially preferable to an opposite or converse mode of conduct or end-state of existence" (Rokeach, 1973, p. 5). The extant literature has found that individual values are an important antecedent to decision-making and behavior in business and organizational contexts (England, 1967; Mayton et al., 1994). Ethical behavior and social responsibility (Meglino and Ravlin, 1998; Shafer et al., 2007; Weber, 1993), as well as environmental concern (Fukukawa et al., 2007; Schultz, 2001; Schultz and Zeleny, 1999; Stern and Dietz, 1994; Stern et al., 1995), are specifically influenced by individual values. Schwartz $(1992,1994)$ has presented a widely used and well-established typology and measurement instrument for individual values. More precisely, he identified ten motivational value types. These value types are interrelated inasmuch as they share motivational goals. As such, they can be grouped into four higher-order value types: self-transcendence (relating to universalism and benevolence), conservation (relating to tradition, conformity and security), self-enhancement (relating to achievement and power) and openness to change (relating to self-direction, stimulation, and hedonism) (for detailed definitions of the individual values see Schwartz (1994)).

Shafer et al. (2007) found a significant relationship between self-transcendence values (universalism and benevolence) as well as conservation values (tradition and conformity) and the perceived importance of ethics and social responsibility. These results are also supported 
Accepted version status August 20, 2018

by Fukukawa et al. (2007), who found similar results with respect to the relationship of values and attitudes toward social and environmental accountability.

\subsection{Individual Characteristics}

In a general context, Schlegelmilch et al. (1996, p. 35) argue that "socio-demographic and personality indicators have had only limited success in profiling consumers according to their environmental purchasing behavior." Analyzing these influencing factors in the specific setting of measuring WTP in a B2C context, De Pelsmacker et al. (2005a) found that the indicator of gender does not have an influence on the WTP for fair trade labelled coffee. Although this result is in line with other studies that examined the influence of gender on ethical decision-making in a general context (e.g., Sikula and Costa, 1994; Tasalikis and OrtizBuonafina, 1994), there are also some studies that provide evidence that gender can have an influence if and when interacting with income or age. Loureiro and Lotade (2005, p. 135) found that "female respondents with high income, and more sensitivity toward environmental issues are more likely to pay a price premium for fair trade and shade grown coffee." Similarly, Auger et al. (2003) found that gender has an influence on the WTP for social product features when interacting with age. Another demographic variable many studies identified as a driver of WTP for sustainable product features is age. Results with respect to age were more consistent when compared to gender, revealing that younger participants have a higher WTP (Loureiro and Lotade, 2005; McGoldrick and Freestone, 2008).

\subsection{Professional Characteristics}

In addition to individual characteristics, professional characteristics may also have an influence on purchasing managers' decision-making. Carter and Jennings (2002) find that purchasing managers have to focus on coordinating with suppliers in order to foster sustainability. This is the case especially when sourcing from emerging markets because 
Accepted version status August 20, 2018

coordination with suppliers is inherently more difficult in those contexts (Amaeshi et al., 2008). Therefore, involvement with and knowledge about suppliers are important drivers of sustainability in purchasing (Ellram et al., 2008). Additionally, purchasing experience (Labuschagne and Brent, 2008), involvement with corporate social responsibility (CSR) (Pullman et al., 2009), and the percentage sourced from emerging markets are criteria that may influence purchasing managers' decision-making. For example, a purchasing manager who sources mostly from emerging markets and has long-term working experience in the field of PSM, especially with respect to CSR, will dispose of more expertise than an employee who recently started working in this specific field. Accordingly, he/she has better knowledge of the possible consequences of non-compliant behavior and, therefore, will also consider stronger environmental and social criteria when selecting new suppliers. Finally, the purchasing volume a purchasing manager is responsible for (Ulaga and Eggert, 2006) and the number of employees reporting to the purchasing managers (Das and Narasimhan, 2001; Olsen et al., 2006) have been identified as factors that influence decisions taken by purchasing managers.

\subsection{Firm-related Characteristics}

The existing literature suggests that firm characteristics, e.g., turnover, number of employees, and industry sector, may influence the propensity to engage with sustainabilityrelated activities (e.g., Baden et al., 2009; Carter, 2000b; Hall, 2000). Larger firms, for example, possess better resources to adopt sustainable business practices or react to new market pressures (Hunt and Auster, 1990; Walley and Whitehead, 1994). In line with these results, Williams et al. (1993) found that small companies with less than 100 employees do not perceive environmental pressures as existent and, consequently, do not consider them as an important part of their business strategy. Furthermore, the industry sector of the focal firm may impact the sustainability-orientation of its business practices (Tate et al., 2010). Hall (2000, p. 459) 
Accepted version status August 20, 2018

states that "consumer pressure is almost entirely focused on recognizable consumer goods," which are predominantly produced by large, multinational firms. In turn, manufacturers of intermediate goods pay little attention to sustainability-related business practices brought forward by customer demand (Williams et al., 1993). Somewhat related to the previous line of reasoning, the distance from the end consumer to the focal firm may also be a decisive factor. The closer the company is to the end consumer, the more it will respond to customers' immediate pressure to engage in certain sustainable business practices (Hall, 2000; Schmidt et al., 2017).

In addition to the mentioned firm-related characteristics, companies are also characterized by their ethical culture. Treviño et al. (1998) identify four elements that constitute ethical culture: (1) ethical behavior of top management, (2) obedience to authority, (3) incentives, and (4) the implementation of a code of conduct (CoC). According to Treviño et al. (1999), top managers can actively influence the behavior of their employees by being role models of ethical behavior. At the same time obedience to authority has been found to significantly harm ethical culture. For example, Goebel et al. (2012) found that within "a purchasing organization with a strong focus on obedience to authority, purchasing managers may be more likely to only fulfill the instructions of a supervisor to select a new supplier at the lowest cost without questioning, for example, labor standards at the supplier's plant." Moreover, Weaver et al. (1999) provide evidence that the implementation of a CoC influences ethical behavior. Similarly, Treviño et al. (2000) also indicate that incentives (i.e., the application of rewards and punishment) are a powerful instrument to influence ethical behavior. In this context, ethical behavior has been clearly linked to decision-making with respect to sustainability. According to Svensson et al. (2010, p. 2) "one cannot have truly sustainable business practices without being focused upon being ethical." Accordingly, ethical behavior 
Accepted version status August 20, 2018

and sustainability are "intertwined and inseparable [because] if one adopts an ethical stance then one should naturally be doing business in a sustainable way" (Svensson et al., 2010, p. 2).

From the previous discussion, we can conclude that values and characteristics have been analyzed on a rather general level with respect to sustainability. So far, however, nobody has analyzed how these factors may influence the WTP of purchasing managers. Therefore, we include these factors in our analysis to obtain insight into the potential drivers of WTP to assure sustainability in a B2B context.

\section{Research Method}

First, we conducted four in-depth interviews with purchasing managers to specify an appropriate purchasing situation and to identify the relevant levels of assurance. Second, we conducted a pretest to identify the range of acceptable and realistic price premiums, as well as the level of sustainability dimensions important to purchasing managers. Third, the results of this preliminary analysis were then used to design a large-scale main study that employs choicebased conjoint analysis (CBC) to estimate purchasing managers' willingness to pay a price premium for different levels of sustainability assurance.

\subsection{Preliminary Study}

\subsubsection{Purchasing Situation}

One of the key objectives of our preliminary study was to identify a hypothetical but realistic purchasing situation, which is both as representative as possible of the decisions purchasing managers face, while at the same being appropriate for conducting a conjoint analysis. Since previous studies (with consumers) have revealed that participants exhibit large differences in their WTP depending on the specific purchasing situation (e.g., Didier and Lucie, 2008; Loureiro and Lotade, 2005), the definition of an appropriate purchasing situation was 
Accepted version status August 20, 2018

particularly critical for our analysis. We conducted semi-structured in-depth interviews with four purchasing professionals to define a suitable purchasing situation. The interviewees came from industry and research. One professional worked as the head of purchasing in a leading international pharmaceutical company. Two professionals worked as consultants and trainers with purchasing managers from different leading companies. Additionally, we interviewed an academic who specialized in purchasing. All of the respondents in this initial phase of our analysis had been dealing with sustainability related issues for at least five years.

The in-depth interviews revealed four essential factors for a purchasing situation in general, and with respect to sustainability in particular: (1) the strategic relevance of the purchased product, (2) the country from which the product is sourced, (3) the number of suppliers available, and (4) the volume and price of the sourced product. Strategic importance is a characteristic that signals purchasing managers to pay special attention to any of the product's properties. The country of origin implicitly reveals information on the average level of compliance with sustainability standards and the risk of misconduct. For example, compliance with sustainability standards in emerging markets is assumed to be lower than in developed countries. Accordingly, the interviewees assigned a high-risk profile to countries from emerging markets. The number of available suppliers is also a decisive factor. A supplier in a monopoly position, for example, would limit options for forcing compliance with different sustainability dimensions because alternative sources are lacking. Therefore, we created a purchasing situation in which purchasing managers faced multiple new suppliers, each of whom provided distinct sustainability characteristics. Finally, the price and volume of the purchased product emerged as an important characteristic in the construction of a representative purchasing situation. Purchasing managers need to know the total amount to pay for a product in order to have a point of reference for the price premium. The in-depth interviews revealed 
Accepted version status August 20, 2018

that a purchasing volume of $€ 800,000$ would be a feasible volume to which the majority of purchasing managers could relate, based on their professional experience.

As a result of our initial interviews with purchasing professionals, we defined the following purchasing situation: purchasing managers have to source a product from one out of multiple new suppliers located in emerging markets, with high strategic importance for the purchasing firm, and which has a purchasing volume of $€ 800,000$.

\subsubsection{Levels of Assurance}

The second objective of the in-depth interviews was to identify relevant levels of assurance of compliance with sustainability dimensions. As highlighted previously, a supplier can take different measures to demonstrate compliance with sustainability dimensions. We intended to group these measures into distinct categories that constitute different levels of assurance for the purposes of this analysis; since there is no prior research that guides us in identifying the right levels of assurance, we chose to apply an inductive approach. We asked the purchasing professionals which levels of assurance they considered to be most relevant to assure compliance, and also asked them to group them into relevant categories ranging from low to high levels of assurance. We provided the purchasing professionals with the UNGC as a reference framework for the different sustainability dimensions because of its wide-ranging recognition and acceptance. Three levels emerged from our interviews with the purchasing professionals: (1) The lowest level of assurance was defined as the suppliers signing a contract with clauses that ensure compliance with one or more dimensions of the UNGC. This level was taken as a base case because it is common practice and induces no, or very little (additional), cost for the suppliers. As outlined previously, however, contractual clauses may be difficult to enforce and thus do not provide very strong assurance of compliant behavior on the supplier's 
side. (2) In addition to this base level, a "medium" level of assurance was identified by the four purchasing professionals: suppliers furnish manuals with guidelines to assure that they are compliant with one or more dimensions of the UNGC. By developing manuals, suppliers demonstrate that they take the subject seriously, but may also already induce higher costs for the suppliers. Still, it provides a more credible measure for demonstrating compliance than contractual clauses. (3) The highest level of assurance included the two lower levels while encompassing the idea that suppliers are audited and agree to unscheduled on-site visits in order to demonstrate that they are compliant with one or more dimensions of the UNGC. External audits, in combination with unscheduled on-site visits, imply considerably higher costs for the suppliers because companies have to establish processes to guarantee that their company is behaving sustainably and receive certificates from external auditing agencies; however, at the same time, they provide the most credible evidence for being compliant.

\subsubsection{Acceptable Price Premium}

After having identified an appropriate purchasing situation and suitable levels of assurance of compliant behavior, we conducted a paper-based pre-test. The main objective of the pre-test was to validate the purchasing situation and the levels of assurance, define the relevant dimensions of sustainability, and to define a relevant range for the price premiums. Knowing the range for feasible price premiums is a prerequisite for designing the stimuli for the conjoint analysis. A total of 18 purchasing managers participated in the pre-test. Participants were selected from different executive courses in purchasing (but not related to sustainability), which were held at the university of one of the authors. The respondents' companies sourced, on average, $14 \%$ of the overall purchasing volume from emerging markets. The respondents' average work experience in the field of purchasing was 14 years. 
Accepted version status August 20, 2018

To identify an appropriate range for the price premiums, we applied a contingent valuation approach. We confronted the respondents with the purchasing situation outlined above and asked them to directly state how much they are willing to pay for alternative levels of assurance for the different dimensions of the UNGC. With respect to the level of assurance, we decided to ask only for the price premium of the lowest and highest levels of assurance, as they are most relevant for determining the lower and upper bound of the price range. The results revealed that the majority of the purchasing managers indicated a rather low price premium, ranging between 0 and $2 \%$. A few participants, however, indicated a high price premium, ranging around $5 \%$.

WTP measurement with conjoint analysis necessitates that we estimate price utility functions based on the price range applied in the conjoint design. Thus, the accuracy of the price utility function depends heavily on the prices used in the design. Based on the results of our preliminary study, we chose $0 \%, 1 \%, 2 \%$, and $5 \%$ as relevant levels. The price range chosen is an outcome of a tradeoff between more accuracy in the lower price range, which more participants indicated in the preliminary study, while at the same time accounting for potential higher price premiums that can only be captured by including them in the research design.

\subsubsection{Dimensions of Sustainability}

The second part of the pretest concentrated on defining the relevant dimensions of sustainability for our study. As described above, we built upon the UNGC, which defines four dimensions with a total of 10 principles. We adapted these principles to a purchasing context (see Table 1).

\begin{tabular}{|l|l|}
\hline Dimensions of UNGC & Principles of UNGC \\
\hline \multirow{4}{*}{ Human Rights } & $\begin{array}{l}\text { Suppliers support and respect the protection of internationally } \\
\text { proclaimed human rights. }\end{array}$ \\
\cline { 2 - 2 } & $\begin{array}{l}\text { Suppliers make sure that they are not complicit in human rights } \\
\text { abuses. }\end{array}$ \\
\hline
\end{tabular}




\begin{tabular}{|l|l|}
\hline \multirow{4}{*}{ Labor Standards } & $\begin{array}{l}\text { Suppliers uphold the freedom of association and the effective } \\
\text { recognition of the right to collective bargaining. }\end{array}$ \\
\cline { 2 - 2 } & Suppliers do not permit any form of forced and compulsory labor. \\
\cline { 2 - 2 } Euppliers do not permit any form of child labor. \\
\cline { 2 - 2 } $\begin{array}{l}\text { Environmental } \\
\text { Standards }\end{array}$ & $\begin{array}{l}\text { Suppliers do not discriminate in respect of employment and } \\
\text { occupation. }\end{array}$ \\
\hline $\begin{array}{l}\text { Suppliers support a precautionary approach to environmental } \\
\text { challenges. }\end{array}$ \\
\cline { 2 - 2 } Suppliers promote greater environmental responsibility. \\
\hline $\begin{array}{l}\text { Suppliers develop and diffuse environmentally friendly } \\
\text { technologies. }\end{array}$ \\
\hline Anti Corruption Policies & $\begin{array}{l}\text { Suppliers proactively work against corruption in all its forms } \\
\text { including extortion and bribery. }\end{array}$ \\
\hline
\end{tabular}

Table 1: Adapted Dimensions of UN Global Compact

In general, we wanted to know whether purchasing professionals bear these factors in mind, and in particular, whether they only think of the four dimensions (meta-level) or if they would distinguish between individual principles. To examine this, we used a 7 point Likerttype scale asking the 18 pretest respondents how important each principle is for their purchasing decisions, with 1 being 'not important' to 7 being 'very important.' We applied correlation analysis to analyze the four dimensions of the UNGC. Correlation analysis revealed high correlations between the single principles of each dimension. Therefore, we concluded that respondents do not (strongly) distinguish between single principles, but mainly focus on the four "global" dimensions of the UNGC. Based on these results, we decided to include the UNGC sustainability dimensions of human rights, labor, environment, and anti-corruption in our analysis.

\subsection{Main Study}

\subsubsection{Dealing with demand effects}

Since purchasing managers' reactions to sustainability topics relate to social norms, one issue of concern in this study may be demand effects (Zizzo, 2010). Zizzo (2010) distinguishes two types of demand effects. The first type is social desirability bias. The second type is 
Accepted version status August 20, 2018

cognitive demand effects that may occur for two reasons. First, they may occur when "subjects try to make sense of the unfamiliar and incompletely defined experimental environment based on the instructions, cues and feedback they receive" (Zizzo, 2010) and, as a result, have biased responses due to the investigator's influence. Second, the very act of belief elicitation, i.e. directing respondents' attention to a specific variable of interest, may change their behavior with regard to this variable, i.e. changing their beliefs (Zizzo, 2010). Although demand effects cannot be completely ruled out in our study, we took several steps to limit them. In the following sections, we will outline in detail how we considered demand effects when we designed the study.

\subsubsection{Data Collection and Response Rate}

The main study consisted of two parts, namely the conjoint experiment and a questionnaire to gather additional information about the respondents and their companies. We used a third-party web-hosting survey service to collect answers for both parts.

The data was collected in Germany in 2009. Although the data was collected a few years ago, we are confident that the dataset is still valid today, as the insights reflect and fit the recent context for several reasons. First, we do not expect that price premiums are subjected to strong volatility. Second, we have measured WTP in terms of relative values, i.e. percentages, and not in absolute terms. Therefore, we do not expect that effects, such as inflation, that may change reference prices will have an influence on the results. Finally, the study was conducted in Germany where macro environmental factors, such as the economic environment, have been quite stable since data collection. Moreover, the speed with which sustainability considerations have been taken up in research and practice has been rather slow (Pagell and Shevchenko, 2014), and lack of compliance with sustainability standards is still a common issue in global 
supply chains (Blome et al., 2017). Thus, the general context in which the data was collected does not substantially differ from the current context in which companies operate.

Germany seemed particularly suitable for our research purposes for two reasons. First, Germany is a highly globalized country with a strong economy (Gygli et al., 2018). German companies source products from all over the world and therefore, the results are relevant for many suppliers on a global scale. Second, as mentioned previously, sustainability is a topic that relates to social norms, so answers may be sensitive to social desirability biases. According to Steenkamp et al. (2010) German respondents are less susceptible to social desirability biases when compared, for example, to US respondents. Their study investigates how susceptible questions relating to environmental consciousness are to social desirability bias. The data for Germany indicates a negligible relationship between social desirability and environmental consciousness. Thus, social desirability biases may be less of an issue when conducting a study in Germany.

Note that the results should be interpreted in the light of this country context. ${ }^{1}$ Country specific factors such as culture or economic development may influence the propensity to pay a price premium for sustainability (Shafer et al., 2007). As such, purchasing managers in other countries may not respond in the very same way.

The recruitment of respondents was as follows: in a first round, we sent an individually addressed e-mail to 286 purchasing professionals who had formerly participated in different trainings and courses (which were not related to sustainability topics). The e-mail contained a short description of the study with a request to participate. We also announced a summary of the results and, to encourage participation, free participation at a closing event where the study

\footnotetext{
${ }^{1}$ We thank an anonymous reviewer for this comment
} 
Accepted version status August 20, 2018

results would be presented. In a second round, we called all participants to inquire if they received our mail and whether they would participate.

If we received approval, we scheduled interviews and sent respondents a link to the questionnaire immediately before the interview. To ensure minimization of demand effects that may occur due to interventions of the interviewer, we developed an interview guideline and trained the research team. The interviewer introduced her/himself and mentioned that the study served as the basis for a new sourcing code to be developed. Thus, the purpose of the study was obfuscated without using deception, as recommended by Zizzo (2010) as one strategy to deal with demand effects.

Respondents answered the questions individually, but the interviewer was on the line to assist the respondent in case she/he had any questions. The respondents entered their answers by themselves and the interviewer did not directly monitor the answers. Thus, we aimed to keep potential interviewer biases as low as possible. At the beginning of the survey, the interviewer explained that an important part of the survey would be a conjoint analysis. After that, she/he explicated the attributes included in the stimuli and the procedure of the conjoint analysis.

We believe that this approach had several advantages. The duration of the interviews was relatively long (particularly because of the conjoint task) and took between 45-60 minutes. Accompanying the interviews on the telephone increased respondents' motivation to fill out the whole questionnaire. It also helped to increase respondents' understanding of the conjoint task and the various attributes that were included.

A total of 59 purchasing professionals participated in our study, leading to a response rate of $20 \%$. For CBC, Johnson suggests a minimum sample size of $\frac{n t a}{c}>500$, where $n$ denotes the number of respondents, $t$ the number of tasks, $a$ the number of alternatives, and 
$c$ the largest number of attributes for one level. In our analysis we have $\frac{n t a}{c}=\frac{59 \times 16 \times 3}{4}=708$, which exceeds the lower bound suggested by Johnson (Orme, 2014). Therefore, we conclude that sample size is large enough for our analysis.

\subsubsection{Measures and Stimuli Development}

We used choice-based conjoint analysis (CBC) to measure WTP for the different sustainability dimensions and levels of assurance. $\mathrm{CBC}$ combines conjoint analysis and discrete choice analysis (Louviere and Woodworth, 1983), posing several advantages (Desarbo et al., 1995; Oppewal et al., 1994). First, CBC closely resembles a real purchase decision because respondents indicate their choice of a product profile within a choice set of alternatives. Using CBC instead of contingent valuation to measure the WTP for sustainable behavior aims to minimize a bias caused by social desirability which is likely to occur in this context (Auger and Devinney, 2007). CBC is supposed to be superior to contingent valuation, which has been used in the majority of previous studies linking sustainability and WTP (e.g., De Pelsmacker et al., 2005a; Elliot and Freeman, 2001; McGoldrick and Freestone, 2008), because decision makers "are forced to balance features, instead of merely indicating the importance of a list of issues using unconstrained responses" (Auger et al., 2008, p. 183).

Prior to the conjoint experiments, the respondents were introduced to the purchasing situation as defined in our pre-test. Additionally, we described in detail the four dimensions of the UNGC and the three levels of assurance in the introductory part of the questionnaire.

We followed Huber and Zwerina (1996) for the development of the orthogonal design of the conjoint study. A total of 16 choice sets, each composed of three different stimuli and one no-choice option, were devised. Each stimulus reflected the characteristics of an individual supplier. The first attribute included the three levels of assurance identified in the in-depth 
Accepted version status August 20, 2018

interviews. The next four attributes included the dimensions of the UNGC, each having attribute levels of yes or no. We included the price premium as the final attribute in the conjoint design with $0 \%, 1 \%, 2 \%$, and $5 \%$ as attribute levels.

\subsubsection{Results Estimation}

We apply $\mathrm{CBC}$ analysis in combination with a Hierarchical Bayes approach, as proposed by Allenby and Ginter (1995) and Arora and Huber (2001). This is the standard estimation procedure for the parameters of a discrete choice model as, for example, illustrated by Allenby et al. (2005), Ding (2007), and Moore (2004). The notion 'hierarchical' refers to the fact that there are two levels of analysis: (1) individuals' partworths are estimated, (2) aggregate measures as average partworth and partworth heterogeneity are derived. The parameters are estimated in an iterative manner (Allenby and Ginter, 1995) and are based on a multinomial logit model, which estimates the probability that a particular respondent will choose a particular alternative in a particular choice task (Ding et al., 2005).

We used Sawtooth Hierarchical Bayes software v4.4.6 to estimate the relevant parameters. In each study, 10,000 preliminary iterations and another 10,000 draws per respondent were used in order to generate parameter estimates. The root likelihood was 0.58 , meaning that our model is approximately 2.32 times better than the 'pure chance' (or 'naïve') model with four choice options in each task.

\section{Data Analysis and Results}

Based on the research questions, we shed light on the average price premium for different levels of assured compliance along the four dimensions of the UNGC for our entire sample population as a first step. In a second step, we provide insights into the choice behavior of individuals for different levels of assured compliance along the dimensions of the UNGC 
with respect to the price premium to be paid. Finally, we investigate the characteristics and individual values that may influence the previously outlined choices.

\subsection{Price Premium for Compliance with the UNGC}

In our first analysis, we determined the average additional price premium that our entire sample population of purchasing managers would be willing to pay to assure the different dimensions of sustainability via the use of manuals and accreditation. We used the minimum level of assurance (i.e., a contract ensuring compliance with all dimensions of the UNGC) as a reference point and determined how much more the purchasing managers would pay for higher levels of assurance (i.e., through manuals or accreditation). We used standard procedures for estimating individuals' WTP (Sichtmann et al., 2011; Wilken and Sichtmann, 2007). First, we approximated each respondent's price utility function for a given combination of level of assurance and sustainability dimension through linear interpolation. Then, we set the WTP as the price premium leading to a utility of zero. Finally, we averaged this price premium across all respondents to obtain the average price premium for our sample population. Table 2 shows the average price premiums that purchasing managers in our sample are willing to pay for the individual dimensions of the UNGC by means of manuals and accreditation.

\begin{tabular}{llcc}
\hline $\begin{array}{l}\text { Dimension(s) } \\
\text { assured by contract }\end{array}$ & $\begin{array}{l}\text { Dimension(s) } \\
\text { assured by manual } \\
\text { or accreditation }\end{array}$ & $\begin{array}{l}\text { Price Premium for } \\
\text { dimensions assured } \\
\text { by manual }\end{array}$ & $\begin{array}{l}\text { Price Premium for } \\
\text { dimensions assured } \\
\text { by accreditation }\end{array}$ \\
\hline HR+LA+AC & EN & $0.39 \%$ & $1.03 \%$ \\
HR+LA+EN & AC & $0.42 \%$ & $1.01 \%$ \\
HR+EN+AC & LA & $0.60 \%$ & $1.25 \%$ \\
LA+EN+AC & HR & $0.14 \%$ & $0.91 \%$ \\
\hline EN & HR+LA+AC & $0.90 \%$ & $2.11 \%$ \\
AC & HR+LA+EN & $0.95 \%$ & $2.52 \%$ \\
LA & HR+EN+AC & $0.88 \%$ & $2.09 \%$ \\
HR & LA+EN+AC & $0.48 \%$ & $1.56 \%$ \\
\hline None & HR+LA+EN+AC & $1.53 \%$ & $2.59 \%$ \\
\hline HR: Human Rights; LA: Labor Standards; EN: Environmental Standards; AC: Anti-Corruption \\
Standards
\end{tabular}


Accepted version status August 20, 2018

Table 2: Price Premiums for Different Levels of Assurance Along the Dimensions of the UNGC

Our results revealed an average price premium of $1.53 \%$ if suppliers assure compliance with all dimensions of the UNGC through manuals, and $2.59 \%$ if they do the same through accreditation. This confirms the results from the interviews conducted during our preliminary study. Purchasing managers not only differentiate between different levels of assurance and prefer, for example, accredited suppliers over non-accredited suppliers, but they also, on average, are willing to pay a price premium for higher levels of assurance of the dimensions of the UNGC. Although manuals are a more credible measure for demonstrating compliance with certain standards than contractual clauses, they cannot be enforced and are also difficult to verify. Still, the purchasing managers in our sample are, on average, willing to pay a price premium for manuals that demonstrate compliance with the UNGC. This is a surprising result which merits more detailed analysis and discussion.

A contract may obligate the supplier to comply with the UNGC; however, as described previously, a contract cannot prevent misbehavior, leaving a high degree of uncertainty on both sides. The buyer cannot be sure if and how the supplier actually complies with the UNGC, while on the other hand, the supplier cannot be sure of meeting the buyer's expectations. Manuals may substantially reduce uncertainty on how the supplier (intends) to comply with the UNGC. The buyer may judge, based on the presented manual, whether their expectations are reflected by the supplier. If not, he/she may renegotiate the contract or specifically ask the supplier to include additional measures; however, some uncertainty still persists at this level. First, whether the supplier actually follows the proceedings described in the manual remains uncertain. Second, the buyer cannot be sure if the measures fully comply with the expectations of its 'responsible' stakeholders who expect the company to take any reasonable measure to 
Accepted version status August 20, 2018

protect the organization from any harm, including loss of reputation. The existence of a price premium for manuals suggests that the purchasing managers in our sample consider manuals as more credible measures than contracts to substantially reduce the risk of non-compliant behavior on the supplier's side. The lack of enforcement of manuals and external validation does not appear to have severe limitations for their credibility. The average price premium of $1.53 \%$ provides evidence that the purchasing managers consider manuals as effective means of protecting their companies from negative consequences associated with non-compliant behavior.

Accreditation by an independent third-party auditor may significantly reduce the remaining uncertainty related to a supplier's compliance with the UNGC. Unscheduled on-site visits allow the auditor to assess whether the supplier actually complies with specified standards. As an expert in compliance with the UNGC, the auditor will also be able to evaluate if the measures taken by the supplier reflect state-of-the-art methods. The same holds true for the supplier, who once certified by the auditor, can be trusted to meet widely accepted standards. Beyond reducing the risk associated with non-compliant behavior of the supplier, accreditation entails another important benefit: working (only) with accredited suppliers provides much higher and more objective credibility towards external stakeholders (especially customers). In case an accredited supplier fails to comply, the purchasing manager can still make use of accreditation certificates to prove that the company has done everything in its power to prevent misbehavior. Clearly, this proof is difficult to establish if only manuals for UNGC compliance are in place. This argument provides an explanation for the higher price premium for accreditation in comparison to manuals. Although manuals also provide assurance that a supplier is compliant, they do not serve as strong a proof as internationally acknowledged accreditation certificates do. We can attribute (at least some part of) the additional price 
Accepted version status August 20, 2018

premium for accreditation to the fact that the involvement of a neutral third party is an objective legitimization directed towards stakeholders of the company. In a more general sense, we can identify two forces that drive the price premium with respect to the level of assurance: the reduction of uncertainty and the increase of external reputation. These forces may not only be influenced by the level of assurance, but also by the individual dimensions of the UNGC. Therefore, we will next discuss the evaluation of the individual dimensions of the UNGC.

The different dimensions of the UNGC induce varying levels of uncertainty to both buyers and suppliers, who in return may induce differing price premiums. For example, a company may have a wide range of knowledge on technical measures to decrease its environmental impact and be able to express the environmental impact in numerous, widely accepted measures, but at the same time may not have any expertise with respect to the social dimension(s) of the UNGC. Thus, a higher level of uncertainty may be related to defining and taking proper measures to comply with the UNGC in the social domain.

Analyzing the price premiums for individual dimensions of the UNGC, we observed that, on average, purchasing managers are willing to pay the highest price premium for the labor dimension $(1.25 \%)$, followed by the environmental (1.03\%), anti-corruption $(1.01 \%)$, and human rights $(0.91 \%)$ dimensions when assuring the particular dimensions by accreditation and all other dimensions only by a contract. In case suppliers only provide manuals, purchasing managers are willing to pay the highest price premium for the labor dimension $(0.60 \%)$, followed by anti-corruption $(0.42 \%)$, environmental $(0.39 \%)$, and human rights $(0.14 \%)$ dimensions when all other dimensions are assured only by contract.

To understand and interpret these results, different factors that might influence the individual price premiums must be considered. Clearly, the price premium should reflect purchasing managers' perceptions of the relative importance of the individual dimension. On 
Accepted version status August 20, 2018

the one hand, this relative importance may be driven by the public attention that certain dimensions receive. Poor working conditions or child labor, for example, may be considered as one violation of accepted sustainability standards, which have a very negative impact if detected. On the other hand, it may also play a role that determines to which extent purchasing managers consider assurance of certain dimensions as credible.

As outlined previously, firms can decide to comply with different sustainability standards, such as the UN Global Compact or GRI Guidelines. None of these standards, however, imply specific processes for how to comply with them (Williams, 2004). As such, in some cases the dimensions do not reflect specific indicators to measure to which extent a supplier is compliant with them. Therefore, companies might not fully trust accreditation of certain dimensions. The UNGC, for example, provides the following principle: "Businesses should work against corruption in all its forms, including extortion and bribery". This principle does not provide as clear a measurable understanding as, for example, the prohibition of child labor. In contrast to well-established certifications for environmental compliance, such as ISO14001, a well-developed, established, and internationally acknowledged certification for social issues did not yet exist at the time of the data collection. ISO 26000 was only introduced in 2010 , and even then as a voluntary guideline.

In this sense, one possible explanation for the lower price premium for the dimension of anti-corruption (if assured by accreditation) might be the fact that control for anti-corruption is more difficult to realize than it is for environmental compliance. Respondents might therefore not have faith that continuous compliance with anti-corruption standards can be assured. In contrast, manuals might provide higher credibility because they describe specific procedures for how companies can deal with the topic. This might explain the slightly higher price premium when compared to the environmental dimension, in the case of manuals being provided for anti- 
Accepted version status August 20, 2018

corruption. A further explanation, especially with respect to the environmental dimension, is the economic benefit caused by improving environmental standards and assuring compliance with them (Carter et al., 2000; Montabon et al., 2000). Carter (2000b) found that "activities in order to facilitate recycling, reuse and resource reduction" have a positive impact on firm performance. As such, purchasing managers might be willing to invest because environmental compliance might lead to savings. Finally, companies assigning less importance to this factor might also explain the difference in price premiums. A corruptive supplier would not cast such a negative cloud over the purchasing company as it would for the violation of labor standards, for example.

The lowest price premium is for the dimension of human rights, which can be explained by its nature. In general, human rights are attributed to a country rather than to a specific company, and they do not have as clearly defined guidelines as labor standards. Therefore, purchasing managers might expect that human rights are inherently covered by labor standards, or there is nothing much an individual supplier could do about this dimension in a particular region or country.

Against this background, observing the price premium for both human rights and labor together and comparing them with the environmental dimension is important. Since human rights and labor may be attributed to the social dimension, this allows us to analyze the two non-economic dimensions of the triple bottom line. The results show that purchasing managers are willing to pay an average price premium of $1.31 \%$ to reduce uncertainty related to the supplier's compliance with the social dimension (i.e., human rights and labor) through accreditation. Comparing this price premium to the environmental dimension $(1.03 \%$ price premium for accreditation), we observe that purchasing managers attribute a higher importance to the social dimension. 
Accepted version status August 20, 2018

The comparison of the price premiums for assuring individual dimensions by accreditation and assuring all dimensions by accreditations provides interesting implications for suppliers who are already accredited for an individual dimension. Adding any individual dimension only yields a marginal increase in the average price premium buyers are willing to pay. As such, the combination of individual dimensions is decisive for receiving the highest price premium and gaining competitive advantages. For example, when assuring three dimensions by accreditation (human rights, labor, environment) and one by contract (anticorruption), the additional WTP amounts to $2.52 \%$. Comparing this result to the price premium when all dimensions are assured (price premium of 2.59\%) demonstrates that the additional accreditation for the dimension of anti-corruption would only provide a marginal price premium of $0.07 \%$.

Summarizing our findings, we can observe that, on average, buyers are willing to pay a price premium for the assurance of individual dimensions as well as their combinations through manuals and accreditation. From a potential supplier's point of view, this already provides important information on whether or not to expect additional revenues when demonstrating compliance. These insights, however, are based purely on average price premiums across the entire sample and do not allow us to infer actual purchasing behavior. As outlined in our introduction, there are arguments for and against the propensity for purchasing managers to pay a price premium. Although TCE provides reasoning as to why purchasing managers should be willing to pay a price premium to assure compliance of their suppliers, they still may align their decisions along the classical purchasing criteria (e.g., price and time). Therefore, we analyze the individual buying behavior of the purchasing managers in our sample in the next section.

\subsection{Individual Choices of Purchasing Managers}


To obtain more detailed insights into the respondents' individual behavior, we analyzed the relative number of purchasing managers who would pay varying price premiums for suppliers that fulfil certain levels of assurance and certain dimensions of sustainability. To obtain these results, we determined how many respondents would be willing to pay a price premium of $1 \%, 2 \%$, and $5 \%$ if compliance was assured through accreditation or manuals for all dimensions of the UNGC, in comparison to a contract only. The results are illustrated in Figure 1.

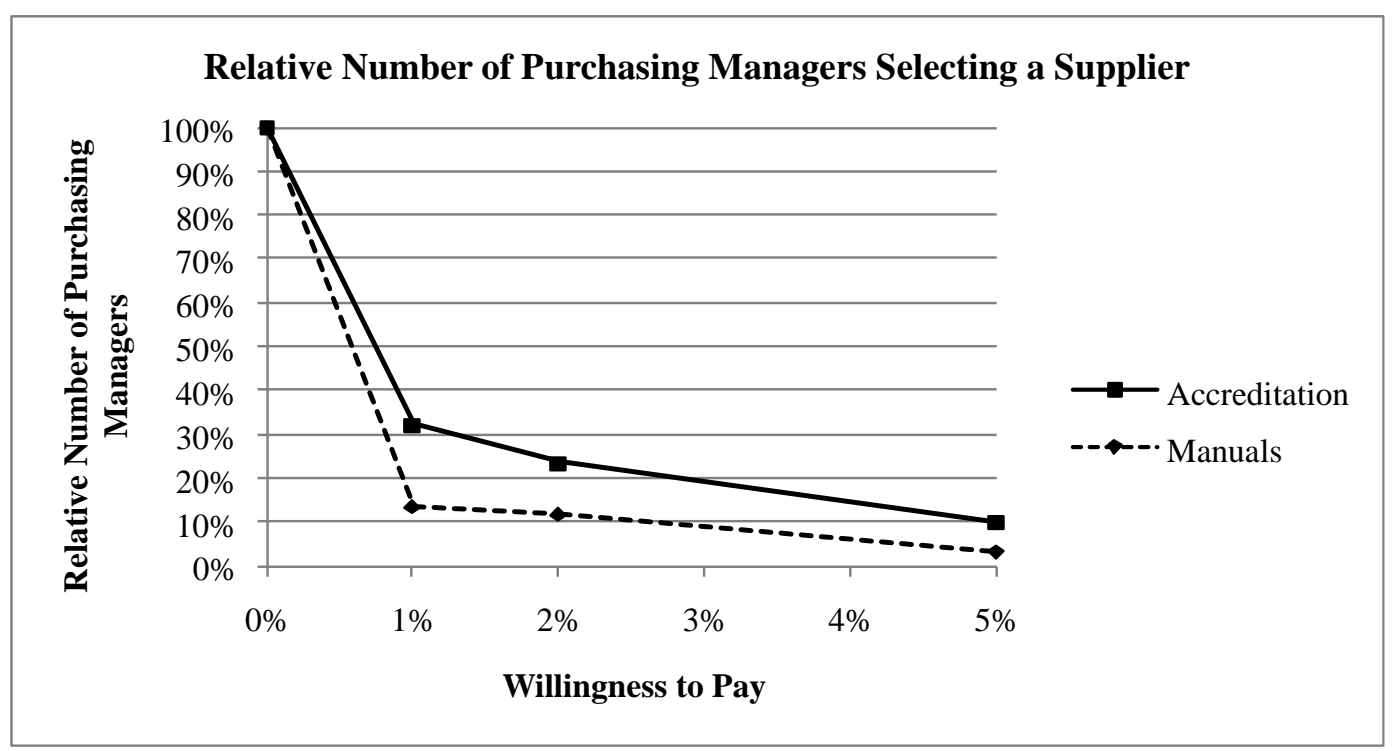

Figure 1: Relative Number of Purchasing Managers Selecting a Supplier

We observed that price elasticity in the range of $0 \%$ to $1 \%$ is very high. This indicates that a large fraction of the respondents in our sample exhibit either a very low WTP or are not willing to incur any additional cost for higher levels of assurance. Only $32.2 \%(13.6 \%)$ would expend an additional $1 \%$ of the purchasing volume for accreditation (manuals). In our sample of purchasing managers, we found one group to be very price sensitive and only willing to pay a very low price premium, while a second group had low price sensitivity and was willing to pay a substantial premium if compliance is assured by manuals or accreditation. Figure 1 shows 
Accepted version status August 20, 2018

that this finding is consistent for both the assurance of compliance through manuals as well as through accreditation. These results also provide some additional insights regarding the average price premium determined in the previous section: the positive average price premium associated with accreditation and manuals is mainly driven by the group of purchasing managers that exhibit low price sensitivity and a high WTP.

\section{Discussing the Drivers of Willingness to Pay (WTP)}

Clearly, we want to know which characteristics distinguish the two groups of purchasing managers in our sample. In our survey we collected a number of individual values, as well as individual, professional, and firm-related characteristics of the respondents (see section 2.3). Some of these variables included in the regression model were measured with multi-item scales based on established measurement scales. These multi-item scales, as well as the sources, are shown in the Appendix.

We applied binary logistic regression analysis to investigate the impact of the different characteristics on the WTP. The dependent binary variable was coded 0 if a respondent belonged to the group with zero or extremely low WTP (i.e., $<0.01 \%$ ) for assuring all dimensions by accreditation, and 1 if the respondent belonged to the group with a higher WTP. 


\begin{tabular}{|c|c|c|c|c|c|c|c|}
\hline \multirow[b]{2}{*}{ Individual Values } & \multirow{2}{*}{$\begin{array}{l}\text { Parameter } \\
\text { Altruistic values }\end{array}$} & \multirow{2}{*}{$\begin{array}{c}\text { Estimate } \\
-0.208\end{array}$} & \multirow{2}{*}{$\begin{array}{c}\text { p-value } \\
0.438\end{array}$} & \multirow{2}{*}{$\begin{array}{c}\begin{array}{c}\text { Standard } \\
\text { Error }\end{array} \\
0.269\end{array}$} & \multirow{2}{*}{$\begin{array}{l}\exp \mathbf{b} \\
0.812\end{array}$} & \multicolumn{2}{|c|}{$\begin{array}{c}\text { Lower/upper } 95 \% \\
\text { confidence interval } \\
\text { of } \exp b\end{array}$} \\
\hline & & & & & & 0.480 & 1.375 \\
\hline & Traditional (or Conservation) values & 0.082 & 0.752 & 0.260 & 1.086 & 0.652 & 1.807 \\
\hline & Self-Enhancement (or Egoistic) values & -0.563 & 0.051 & 0.289 & 0.569 & 0.323 & 1.004 \\
\hline & Openness to change values & -0.210 & 0.437 & 0.271 & 0.810 & 0.477 & 1.377 \\
\hline \multirow[t]{2}{*}{ Individual Characteristics } & Gender & -0.595 & 0.416 & 0.731 & 0.552 & 0.132 & 2.312 \\
\hline & Age & -0.037 & 0.303 & 0.036 & 0.964 & 0.899 & 1.034 \\
\hline \multirow[t]{7}{*}{ Professional Characteristics } & Annual purchasing volume of interviewee & 0.000 & 0.292 & 0.000 & 1.000 & 1.000 & 1.000 \\
\hline & Number of employees reporting to interviewee & -0.004 & 0.847 & 0.019 & 0.996 & 0.959 & 1.035 \\
\hline & Percentage sourced from emerging markets by interviewee & 0.015 & 0.410 & 0.018 & 1.015 & 0.979 & 1.053 \\
\hline & Work experience in purchasing & -0.057 & 0.238 & 0.048 & 0.945 & 0.859 & 1.039 \\
\hline & Years involved with CSR & -0.080 & 0.172 & 0.058 & 0.923 & 0.824 & 1.035 \\
\hline & Involvement with suppliers & -0.078 & 0.684 & 0.191 & 0.925 & 0.637 & 1.345 \\
\hline & Knowledge about suppliers & -0.044 & 0.858 & 0.244 & 0.957 & 0.594 & 1.544 \\
\hline \multirow[t]{9}{*}{ Firm-Related Characteristics } & Annual turnover & 0.000 & 0.205 & 0.000 & 1.000 & 1.000 & 1.000 \\
\hline & Turnover spent on CSR & 0.153 & 0.660 & 0.347 & 1.165 & 0.590 & 2.300 \\
\hline & Annual purchasing volume & 0.000 & 0.255 & 0.000 & 1.000 & 1.000 & 1.000 \\
\hline & Percentage sourced from emerging markets & 0.025 & 0.242 & 0.021 & 1.025 & 0.983 & 1.069 \\
\hline & Number of full time employees & 0.000 & 0.238 & 0.000 & 1.000 & 1.000 & 1.000 \\
\hline & $\begin{array}{l}\text { Number of full time employees of the purchasing } \\
\text { department }\end{array}$ & 0.000 & 0.663 & 0.000 & 1.000 & 1.000 & 1.000 \\
\hline & Distance to end customer & -0.164 & 0.348 & 0.174 & 0.849 & 0.603 & 1.195 \\
\hline & Industry & 0.152 & 0.404 & 0.183 & 1.165 & 0.814 & 1.665 \\
\hline & Company is member of the UNGC & -0.102 & 0.847 & 0.531 & 0.903 & 0.319 & 2.558 \\
\hline \multirow[t]{4}{*}{ Ethical Culture } & Ethical Behavior of Top Management & -0.037 & 0.891 & 0.269 & 0.964 & 0.569 & 1.632 \\
\hline & Obedience to authority & -0.971 & 0.005 & 0.345 & 0.379 & 0.193 & 0.745 \\
\hline & Incentives & -0.055 & 0.839 & 0.268 & 0.947 & 0.559 & 1.602 \\
\hline & Code of Conduct & 0.142 & 0.621 & 0.287 & 1.152 & 0.656 & 2.023 \\
\hline
\end{tabular}

Table 3: Total Effects of Characteristic Variables 
We determined the total effects of the characteristics variables one at a time. The results of our analysis are displayed in Table 3.

Although previous research in a B2C context found that individual characteristics (i.e., demographics) influence the WTP for sustainability (e.g., Auger et al., 2008; De Pelsmacker et al., 2005a), we could not find such effects in our data. We did not observe a significant influence of professional characteristics (e.g., years of experience in purchasing) for all but one firmrelated characteristic. The affiliation of a company with the UNGC also did not have a significant effect. Since our statistical analyses did not immediately yield any explanations, we carefully examined the different groups of purchasing managers. The group of price insensitive respondents represented a variety of different industries (that were also represented in the group of price sensitive purchasing managers). We even found instances in which respondents from the same department of a single firm belonged to both groups. Therefore, individual traits likely influence the WTP for sustainability. Our results partially support this assumption. Our analysis revealed a significant negative influence of self-enhancement values on the willingness to pay a price premium. The results suggest that a purchasing manager who assigns a high value to authority, wealth, and the influence on subordinates will be less willing to pay a price premium. Surprisingly, we did not find a significant effect of self-transcendence on WTP. In particular, this value involves green and social aspects (see the specific measurement items in the Appendix for this value). Obviously, these do not directly translate to sustainable behavior in an organizational context. This finding should of course be viewed in light of the limitations of this study (small sample size, specific cultural context of Germany, and focus on specific values).

We also found that, on a company level, the existence of an ethical culture characterized by obedience to authority has a negative impact on the willingness to pay a price premium. 
Both constructs (i.e., self-enhancement values and obedience to authority) reflect similar characteristics, albeit on an individual and a firm-specific level. Self-enhancement values by definition encompass a high emphasis on authority on an individual's level, while obedience to authority as part of the ethical culture of a firm refers to a (very similar) characteristic at the organizational level. In our sample, a low WTP for sustainability may be attributed not only to an individual purchasing manager with high self-enhancement values (including obedience to authority), but also to an organizational culture that fosters obedience to authority. Surprisingly, we did not find a significant correlation between obedience to authority as an element of ethical culture and self-enhancement values. This suggests that both factors can have separate effects and are not necessarily present at the same time, i.e., a purchasing manager with low selfenhancement values may exhibit a low WTP if working in an organization characterized by a high level of obedience to authority.

\section{Conclusions and Implications for Research and Practice}

We set out with the research question: Are purchasing managers (of buying companies) willing to pay a price premium to assure compliance with sustainability standards? $\mathrm{We}$ presented two lines of reasoning, one that PSM's cost-orientation will prevent WTP, and the other, based on TCE, that there would be WTP. Looking at the main results, purchasing managers indeed show willingness to pay a substantial price premium for manuals that demonstrate compliance with the UNGC. Furthermore, the results show that this WTP is mostly influenced (negatively) by self-enhancement (on the individual level) and/or obedience to authority (on the organizational level), but neither by company, affiliation with the UNGC, gender, or years of experience. Moreover, WTP is higher for the social than for the 
environmental dimension, and the marginal effect of accreditation on WTP depends on which combinations of dimensions are accredited.

\subsection{Limitations and Suggestions for Future Research}

We have identified key characteristics and values that show an influence on the WTP for sustainability; however, besides obedience to authority as a part of ethical culture and selfenhancement values, we did not find any characteristic that influences WTP to assure compliance with sustainability standards. Therefore, future studies should focus on further characteristics that may positively or negatively influence WTP. One example is the Decisional Balance Scale (DBS) to investigate buyers' trade-off between "the personal cost of a potentially higher-priced product against the social benefit of a potentially more environmentally friendly purchase" (McGoldrick and Freestone, 2008, p. 189). The DBS could contributes to the further understanding of cognitive and motivational aspects of sustainable decision-making of purchasing managers (Janis and Mann, 1977; Velicer et al., 1985). Following Holt and Laury (2002), future research could account for individual risk preferences and, correspondingly, the individuals' assessment of the risk that a supplier would act unsustainably, and then become disclosed. Subsequently, evaluating the expected negative impact of either one of those factors on the firm might provide a better understanding of how individuals' inherent preferences regarding risk and sustainability are affected by corporate values, e.g. moderated or emphasized.

Similarly, more explicit consideration of the level of "greenness" inherent to the individual decision maker, in this case the purchasing manager, could be worthwhile. While we capture "protecting the environment and preserving the nature" as an item of the selftranscendence value, we do not consider additional variables related to the "greenness" of 
purchasing managers. For example, individual green behavior such as private recycling behavior (Marans and Lee, 1993), environmental actions at home (Tudor et al., 2007), private green purchasing behavior, or green attitudes, such as environmental awareness or attitudes towards the environment and environmental behavior (Coskun, 2018), could be examined.

A second limitation is the consideration of only one theory. Besides TCE, we did not focus on a specific theory, such as attribution theory, crime theory, or prospect theory, which could explain our results in more detail. According to attribution theory, for example, an individual always evaluates who or what may be blamed for the outcome of a cause (locus of causality), how much he/she might be held responsible for an outcome (controllability), and whether the cause will remain constant or not in the future (stability) (Weiner, 1986). If a purchasing manager perceives that he/she will not be held responsible for an outcome, or the outcome might not have a substantial impact, he/she might not be willing to pay a price premium.

A third limitation of our study is the regional boundary (Germany) in which it was performed. The related cultural context might have influenced our results (e.g., Copper et al., 2000; Goffin et al., 2006; Shafer et al., 2007).

Moreover, as the data is from 2009, WTP for sustainability may have changed along with increasing maturity of sustainability issues in companies and demographic changes in the workforce. As mentioned earlier, however, the speed with which sustainability considerations have been taken up in research and practice has been rather slow (Pagell and Shevchenko, 2014). In addition, even if sustainability issues have become more important in the past decade, our analysis is a rather conservative estimation of the price premium. Such an interpretation increases the validity of the main message of our study, which is that purchasing managers are, in principle, ready to pay a price premium for different levels of assurance of sustainability. 
Nevertheless, a replication of our study with fresh data, as well as in other cultural contexts, might deliver further insights. There is a possibility that the relative importance of environmental versus social issues might have changed. One suggestion would be to use the now available and more specific ISO 14001:2015, rather than the chosen UNGC, to further test the effects.

Fourth, the results were estimated on the basis of the responses of 59 purchasing professionals. As such, the generalizability of our results is limited. The sample size is rather small, and future studies could attempt to increase the sample size to further study the effects of this research and potentially offer various alternative explanations. Furthermore, purchasing professionals came from different company levels as well as from different industries. Future studies should study a larger sample population and consider specific company levels (e.g., operative and strategic purchasing managers) in order to consider additional influencing factors that have explanatory power (Treviño et al., 2015).

Fifth, we have outlined how we have tried to minimize demand effects in our study. Although we were very careful in limiting social desirability biases and cognitive demand effects, we cannot completely rule them out. This should be kept in mind when interpreting the study results. Future studies should be particularly careful when considering demand effects in their design, and make efforts to further reduce them. Attribution theory, mentioned above with regards to our second limitation, might be particularly useful in this context.

Finally, we only considered the WTP of buying companies without analyzing the effect of accreditation of suppliers in our study. Therefore, future research might concentrate on studying the dyadic relationship. By obtaining information from both buyers and suppliers, 
research would be able to define the optimal solution for the level of assurance and the dimensions of sustainability on both sides of the dyadic relationship.

\subsection{Managerial Implications}

From a managerial perspective, our results pose a significant challenge for suppliers, who would clearly like to know to which extent their (corporate) customers value an additional effort for demonstrating compliance with sustainability standards. Ideally, a supplier would like to have buyers with a positive and homogenous WTP for higher levels of assurance. This would enable the supplier to determine the optimal level of assurance and price premium for a given customer base. Although we can hardly generalize our results, they do suggest that a supplier will likely not face such homogenous buyers, but individual purchasing managers with individual preferences and WTP. In such situations, a supplier charging a price premium for certain measures demonstrating compliance with sustainability standards would be difficult. Even if a differential pricing approach may in general be feasible, our results suggest that the WTP is driven by characteristics pertaining to individuals and are not easily observable from the outside. Accordingly, a segmentation of the supplier's customer base seems inherently difficult.

From a buying companies' point of view, our results provide insights for managers on how to better incorporate sustainability in the PSM function. Since our results indicate that selfenhancement values play an important role in assessing the WTP for sustainability, companies should develop clearly defined guidelines that limit the freedom of action of each purchasing manager with respect to sustainability, e.g., by sanctioning non-compliant behavior. More specifically, these guidelines have to assure that purchasing managers' decision-making with respect to social and environmental sustainability is not guided by egoistic and selfenhancement values. Furthermore, our results suggest that the ethical culture of a company may 
influence how purchasing managers evaluate the activities a supplier takes (i.e., in the sense of being willing to pay a price premium) to assure compliance with sustainability standards. Managers may be able to influence decision-making by adapting new incentive mechanisms that assign higher values to sustainability criteria, while at the same time putting less emphasis on economic criteria in order to positively influence the ethical culture of a company. Clear communication, e.g. a sourcing code, may additionally enhance employees' understanding of the values that form the ethical culture of the company.

\section{Acknowledgements}

The authors gratefully acknowledge the insightful comments of David Wuttke and Philipp Ecken on earlier versions of this paper. Moreover, they would like to thank the Journal's editors and reviewers involved for their very constructive and helpful comments. 


\section{References}

Abbey, J.D., Blackburn, J.D., Guide, V.D.R., 2015. Optimal pricing for new and remanufactured products. Journal of Operations Management 36, 130-146

Allenby, G., Fennell, G., Huber, J., Eagle, T., Gilbride, T., Horsky, D., Kim, J., Lenk, P., Johnson, R., Ofek, E., Orme, B., Otter, T., Walker, J., 2005. Adjusting Choice Models to Better Predict Market Behavior. Marketing Letters 16, 197-208

Allenby, G.M., Ginter, J.L., 1995. Using Extremes to Design Products and Segment Markets. Journal of Marketing Research 32, 392-403

Amaeshi, K.M., Osuji, O.K., Nnodim, P., 2008. Corporate Social Responsibility in Supply Chains of Global Brands: A Boundaryless Responsibility? Clarifications, Exceptions and Implications. Journal of Business Ethics 81, 223-234

Arnot, C., Boxall, P.C., Cash, S.B., 2006. Do Ethical Consumers Care About Price? A Revealed Preference Analysis of Fair Trade Coffee Purchases. Canadian Journal of Agricultural Economics 54, 555-565

Arora, N., Huber, J., 2001. Improving Parameter Estimates and Model Prediction by Aggregate Customization in Choice Experiments. Journal of consumer research 28, 273-283

Auger, P., Burke, P., Devinney, T.M., Louviere, J.J., 2003. What Will Consumers Pay for Social Product Features? Journal of Business Ethics 42, 281-304

Auger, P., Devinney, T.M., 2007. Do What Consumers Say Matter? The Misalignment of Preferences with Unconstrained Ethical Intentions. Journal of Business Ethics 76, 361383

Auger, P., Devinney, T.M., Louviere, J.J., Burke, P.F., 2008. Do social product features have value to consumers? International Journal of Research in Marketing 25, 183-191

Baden, D.A., Harwood, I.A., Woodward, D.G., 2009. The effect of buyer pressure on suppliers in SMEs to demonstrate CSR practices: An added incentive or counter productive? European Management Journal 27, 429-441

Bals, L., Tate, W.L., 2018. Sustainable Supply Chain Design in Social Businesses: Advancing the Theory of Supply Chain. Journal of Business Logistics 39, 57-79

Bank, T.W., 2009. Doing Business 2010: Reforming through Difficult Times. The International Bank for Reconstruction and Development, Washington 
Basu, K., Palazzo, G., 2008. Corporate Social Responsibility: A Process Model of Sensemaking. Academy of Management Review 33, 122-136

Beske, P., Koplin, J., Seuring, S., 2008. The use of environmental and social standards by German first-tier suppliers of the Volkswagen AG. Corporate Social Responsibility and Environmental Management 15, 63-75

Blome, C., Foerstl, K., Schleper, M.C., 2017. Antecedents of green supplier championing and greenwashing: An empirical study on leadership and ethical incentives. Journal of Cleaner Production 152, 339-350

Boyd, D.E., Spekman, R.E., Kamauff, J.W., Werhane, P., 2007. Corporate Social Responsibility in Global Supply Chains: A Procedural Justice Perspective. Long Range Planning 40, 341-356

Caniato, F., Caridi, M., Crippa, L., Moretto, A., 2012. Environmental sustainability in fashion supply chains: An exploratory case based research. International Journal of Production Economics 135, 659-670

Carter, C., 2000a. Ethical issues in international buyer-supplier relationships: a dyadic examination. Journal of Operations Management 18, 191-208

Carter, C.R., 2000b. Precursors of Unethical Behavior in Global Supplier Management. The Journal of Supply Chain Management 36, 45-56

Carter, C.R., 2005. Purchasing social responsibility and firm performance: The key mediating roles of organizational learning and supplier performance. International Journal of Physical Distribution \& Logistics Management 35, 177-194

Carter, C.R., Carter, J.R., 1998. Interorganizational Determinants of Environmental Purchasing: Initial Evidence from the Consumer Products Industries. Decision Sciences 29, 659-684

Carter, C.R., Jennings, M.M., 2002. Logistics Social Responsibility: An Integrative Framework. Journal of Business Logistics 23, 145-180

Carter, C.R., Jennings, M.M., 2004. The Role of Purchasing in Corporate Social Responsibility: A Structural Equation Analysis. Journal of Business Logistics 25, 145-186

Carter, C.R., Kale, R., Grimm, C.M., 2000. Environmental purchasing and firm performance: an empirical investigation. Transportation Research Part E: Logistics and Transportation Review 36, 219-228 
Carter, C.R., Rogers, D.S., 2008. A framework of sustainable supply chain management: moving toward new theory. International Journal of Physical Distribution \& Logistics Management 38, 360-387

Copper, R.W., Frank, G.L., Kemp, R.A., 2000. A multinational comparison of key ethical issues, helps and challenges in the purchasing and supply management profession: The key implications for business and the professions. Journal of Business Ethics 23, 83100

Coskun, A., 2018. Understanding Green Attitudes, In: Quoquab, F., Thurasamy, R., Mohammad, J. (Eds), Driving Green Consumerism Through Strategic Sustainability Marketing. IGI Global, pp. 51-71

Côté, R.P., Lopez, J., Marche, S., Perron, G.M., Wright, R., 2008. Influences, practices and opportunities for environmental supply chain management in Nova Scotia SMEs. Journal of Cleaner Production 16, 1561-1570

Das, A., Narasimhan, R., 2001. Process-technology fit and its implications for manufacturing performance. Journal of Operations Management 19, 521-540

De Pelsmacker, P., Driesen, L., Rayp, G., 2005a. Do Consumers Care about Ethics? Willingness to Pay for Fair-Trade Coffee. The Journal of Consumer Affairs 39, 363385

De Pelsmacker, P., Janssens, W., Sterckx, E., Mielants, C., 2005b. Consumer preferences for the marketing of ethically labelled coffee. International Marketing Review 22, 512-530

Desarbo, W.S., Ramaswamy, V., Cohen, S.H., 1995. Market segmentation with choice-based conjoint analysis. Marketing Letters 6, 137-147

Didier, T., Lucie, S., 2008. Measuring consumer's willingness to pay for organic and Fair Trade products. International Journal of Consumer Studies 32, 479-490

Ding, M., 2007. An Incentive-Aligned Mechanism for Conjoint Analysis. Journal of Marketing Research 44, 214-223

Ding, M., Grewal, R., Liechty, J., 2005. Incentive-Aligned Conjoint Analysis. Journal of Marketing Research 42, 67-82

Eckert, R.A., 2007. Testimony of Robert A. Eckert. 1-14

Elkington, J., 1998. Cannibals with forks: the triple bottom line of 21 st century business. New Society Publishers, Gabriola Island, BC 
Elliot, K.A., Freeman, R.B., 2001. White Hats or Don Quixotes? Human Rights Vigilantes in the Human Rights. Working Paper No. 8102. Cambridge, MA: National Bureau of Economic Research

Ellram, L.M., Tate, W., Carter, C.R., 2008. Applying 3DCE to environmentally responsible manufacturing practices. Journal of Cleaner Production 16, 1620-1631

England, G.W., 1967. Personal Value Systems of American Managers. Academy of Management Journal 10, 53-68

FLO, 2010. What is Fairtrade? Fairtrade Labelling Organizations International, Cologne

Foerstl, K., Azadegan, A., Leppelt, T., Hartmann, E., 2015. Drivers of Supplier Sustainability: Moving Beyond Compliance to Commitment. Journal of Supply Chain Management $51,67-92$

Fritzsche, D.J., Oz, E., 2007. Personal Values' Influence on the Ethical Dimension in Decision Making. Journal of Business Ethics 75, 10

Fukukawa, K., Shafer, W.E., Lee, G.M., 2007. Values and Attitudes Toward Social and Environmental Accountability: a Study of MBA Students. Journal of Business Ethics $71,381-394$

Giunipero, L.C., Hooker, R.E., Denslow, D., 2012. Purchasing and supply management sustainability: Drivers and barriers. Journal of Purchasing and Supply Management 18, 258-269

Goebel, P., Reuter, C., Pibernik, R., Sichtmann, C., 2012. The influence of ethical culture on supplier selection in the context of sustainable sourcing. International Journal of Production Economics 140, 7-17

Goffin, K., Lemke, F., Szwejczewski, M., 2006. An exploratory study of 'close' suppliermanufacturer relationships. Journal of Operations Management 24, 189-209

Grandia, J., Steijn, B., Kuipers, B., 2015. It is not easy being green: increasing sustainable public procurement behaviour. Innovation: The European Journal of Social Science Research 28, 243-260

Green, P.E., Srinivasan, V., 1978. Conjoint Analysis in Consumer Research: Issues and Outlook. Journal of consumer research 5, 103-123

Gualandris, J., Klassen, R.D., Vachon, S., Kalchschmidt, M., 2015. Sustainable evaluation and verification in supply chains: Aligning and leveraging accountability to stakeholders. Journal of Operations Management 38, 1-13 
Gygli, S., Haelg, F., Sturm, J.-E., 2018. The KOF Globalisation Index - Revisited. KOF Swiss Economic Institute, ETH Zurich

Haddock-Fraser, J.E., Tourelle, M., 2010. Corporate motivations for environmental sustainable development: exploring the role of consumers in stakeholder engagement. Business Strategy and the Environment 19, 527-542

Hahn, T., Figge, F., Pinkse, J., Preuss, L., 2010. Trade-offs in corporate sustainability: you can't have your cake and eat it. Business Strategy and the Environment 19, 217-229

Hahn, T., Figge, F., Pinkse, J., Preuss, L., 2017. A Paradox Perspective on Corporate Sustainability: Descriptive, Instrumental, and Normative Aspects. Journal of Business Ethics 148, 235-248

Hall, J., 2000. Environmental supply chain dynamics. Journal of Cleaner Production 8, 455471

Handfield, R., Walton, S.V., Sroufe, R., Melnyk, S.A., 2002. Applying environmental criteria to supplier assessment: A study in the application of the Analytical Hierarchy Process. European Journal of Operational Research 141, 70-87

Hayward, T., 2010. Full statement of BP chief Tony Hayward's testimony in front of Congress, International Business Times, New York

Holt, C.A., Laury, S.K., 2002. Risk Aversion and Incentive Effects. The American Economic Review 92, 1644-1655

Houston, M.B., Johnson, S.A., 2000. Buyer-Supplier Contracts Versus Joint Ventures: Determinants and Consequences of Transaction Structure. Journal of Marketing Research 37, 1-15

Hsu, C.-W., Hu, A.H., 2009. Applying hazardous substance management to supplier selection using analytic network process. Journal of Cleaner Production 17, 255-264

Huber, J., Zwerina, K., 1996. The Importance of Utility Balance in Efficient Choice Designs. Journal of Marketing Research 33, 307-317

Hunt, C.B., Auster, E.R., 1990. Proactive Environmental Management: Avoiding the Toxic Trap. Sloan Management Review 31, 7-18

Hutchins, M.J., Sutherland, J.W., 2008. An exploration of measures of social sustainability and their application to supply chain decisions. Journal of Cleaner Production 16, 1688-1698 
Jackson, R.W., Neidell, L.A., Lunsford, D.A., 1995. An Empirical Investigation of the Differences in Goods and Services as Perceived by Organizational Buyers. Industrial Marketing Management 24, 99-108

Janis, I.L., Mann, L., 1977. Decision Making: A Psychological Analysis of Conflict, Choice, and Commitment. Free Press, New York

Johnsen, T.E., Miemczyk, J., Howard, M., 2017. A systematic literature review of sustainable purchasing and supply research: Theoretical perspectives and opportunities for IMPbased research. Industrial Marketing Management 61, 130-143

Kalafatis, S.P., Pollard, M., East, R., Tsogas, M.H., 1999. Green marketing and Ajzen's theory of planned behaviour: a cross-market examination. Journal of Consumer Marketing 16, $441-460$

Kovács, G., 2008. Corporate environmental responsibility in the supply chain. Journal of Cleaner Production 16, 1571-1578

Labuschagne, C., Brent, A.C., 2008. An industry perspective of the completeness and relevance of a social assessment framework for project and technology management in the manufacturing sector. Journal of Cleaner Production 16, 253-262

Linton, J., Klassen, R., Jayaraman, V., 2007. Sustainable supply chains: An introduction. Journal of Operations Management 25, 1075-1082

Loureiro, M.L., Lotade, J., 2005. Do fair trade and eco-labels in coffee wake up the consumer conscience? Ecological Economics 53, 129-138

Louviere, J.J., Woodworth, G., 1983. Design and Analysis of Simulated Consumer Choice or Allocation Experiments: An Approach Based on Aggregate Data. Journal of Marketing Research 20, 350-367

Marans, R.W., Lee, Y.-J., 1993. Linking recycling behavior to waste management planning: A case study of office workers in Taiwan. Landscape and Urban Planning 26, 203-214

March, J.G., Shapira, Z., 1987. Managerial Perspectives on Risk and Risk Taking. Management Science 33, 1404-1418

Matos, S., Hall, J., 2007. Integrating sustainable development in the supply chain: The case of life cycle assessment in oil and gas and agricultural biotechnology. Journal of Operations Management 25, 1083-1102

Mayton, D.M., Ball-Rokeach, S.J., Loges, W.E., 1994. Human Values and Social Issues: An Introduction. Journal of Social Issues 50, 1-8 
McClenachan, L., Dissanayake, S.T.M., Chen, X., 2016. Fair trade fish: consumer support for broader seafood sustainability. Fish and Fisheries 17, 825-838

McGoldrick, P.J., Freestone, O.M., 2008. Ethical product premiums: antecedents and extent of consumers' willingness to pay. The International Review of Retail, Distribution and Consumer Research 18, 185-201

Meglino, B.M., Ravlin, E.C., 1998. Individual Values in Organizations: Concepts, Controversies, and Research. Journal of Management 24, 351-389

Miemczyk, J., Wilding, R., Johnsen, T.E., Macquet, M., 2012. Sustainable purchasing and supply management: a structured literature review of definitions and measures at the dyad, chain and network levels. Supply Chain Management: An International Journal $17,478-496$

Mintcheva, V., 2005. Indicators for environmental policy integration in the food supply chain (the case of the tomato ketchup supply chain and the integrated product policy). Journal of Cleaner Production 13, 717-731

Monczka, R.M., Handfield, R.B., Giunipero, L.C., Patterson, J.L., 2016. Purchasing and supply chain management, Sixth edition. ed. Cengage Learning, Boston, MA

Montabon, F., Melnyk, S.A., Sroufe, R., Calantone, R.J., 2000. ISO 14000: Assessing Its Perceived Impact on Corporate Performance. The Journal of Supply Chain Management $36,4-16$

Montabon, F., Pagell, M., Wu, Z., 2016. Making Sustainability Sustainable. Journal of Supply Chain Management 52, 11-27

Montiel, I., 2008. Corporate Social Responsibilty and Corporate Sustainability: Separate Pasts, Common Futures. Organization \& Environment 21, 245-269

Moore, W.L., 2004. A Cross-Validity Comparison of Rating-Based and Choice-Based Conjoint Analysis Models. International Journal of Research in Marketing 21, 299-312

Olsen, B.J., Nelson, D.L., Parayitam, S., 2006. Managing Aggression in Organizations: What Leaders Must Know. Leadership and Organization Development Journal 27, 384-398

Oppewal, H., Louviere, J.J., Timmermans, H.J.P., 1994. Modeling Hierarchical Conjoint Processes with Integrated Choice Experiments. Journal of Marketing Research 31, 92 105

Orme, B.K., 2014. Getting Started with Conjoint Analysis: Strategies for Product Design and Pricing Research, 3rd ed. Research Publishers LCC, Glendale, Calif. 
Pagell, M., Shevchenko, A., 2014. Why Research in Sustainable Supply Chain Management Should Have no Future. Journal of Supply Chain Management 50, 44-55

Pagell, M., Wu, Z., 2009. Building a More Complete Theory of Sustainable Supply Chain Management Using Case Studies of 10 Exemplars. Journal of Supply Chain Management 45, 37-56

Pullman, M.E., Maloni, M.J., Carter, C.R., 2009. Food for Thought: Social Versus Environmental Sustainability Practices and Performance Outcomes. Journal of Supply Chain Management 45, 38-54

Reuter, C., Foerstl, K., Hartmann, E., Blome, C., 2010. Sustainable Global Supplier Management: The Role of Dynamic Capabilities in Achieving Competitive Advantage. Journal of Supply Chain Management 46, 45-63

Reuter, C., Goebel, P., Foerstl, K., 2012. The impact of stakeholder orientation on sustainability and cost prevalence in supplier selection decisions. Journal of Purchasing and Supply Management 18, 270-281

Roberts, S., 2003. Supply Chain Specific? Understanding the Patchy Success of Ethical Sourcing Initiatives. Journal of Business Ethics 44, 159-170

Rokeach, M.J., 1973. The Nature of Human Values. The Free Press, New York

Schlegelmilch, B.B., Bohlen, G.M., Diamantopoulos, A., 1996. The link between green purchasing decisions and measures of environmental consciousness. European Journal of Marketing 30, 35-55

Schmidt, C.G., Foerstl, K., Schaltenbrand, B., 2017. The Supply Chain Position Paradox: Green Practices and Firm Performance. Journal of Supply Chain Management 53, 3-25

Schneider, L., Wallenburg, C.M., 2012. Implementing sustainable sourcing-Does purchasing need to change? Journal of Purchasing and Supply Management 18, 243-257

Schultz, W.P., 2001. The Structure of Environmental Concern: Concern For Self, Other People, and The Biosphere. Journal of Environmental Psychology 21, 327-339

Schultz, W.P., Zeleny, L., 1999. Values as Predictors of Environmental Attitudes: Evidence for Consistency Across 14 Countries. Journal of Environmental Psychology 19, 255-265

Schwartz, S.H., 1992. Universals in the Content and Structure of Values: Theoretical Advances and Empirical Tests in 20 Countries. Academic Press, Boston

Schwartz, S.H., 1994. Are There Universal Aspects in the Structure and Contents of Human Values? Journal of Social Issues 50, 19-45 
Seuring, S., Müller, M., 2008. From a literature review to a conceptual framework for sustainable supply chain management. Journal of Cleaner Production 16, 1699-1710

Shafer, W.E., Fukukawa, K., Lee, G.M., 2007. Values and the Perceived Importance of Ethics and Social Responsibility: The U.S. versus China. Journal of Business Ethics 70, 256276

Shang, G., Pekgün, P., Ferguson, M., Galbreth, M., 2017. How much do online consumers really value free product returns? Evidence from eBay. Journal of Operations Management 53-56, 45-62

Sichtmann, C., Wilken, R., Diamantopoulos, A., 2011. Estimating Willingness-to-pay with Choice-based Conjoint Analysis - Can Consumer Characteristics Explain Variations in Accuracy? British Journal of Management 22, 628-645

Sikula, A.S., Costa, A.D., 1994. Are Women More Ethical than Men? Journal of Business Ethics 13, 859-871

Steenkamp, J.-B.E.M., de Jong, M.G., Baumgartner, H., 2010. Socially Desirable Response Tendencies in Survey Research. Journal of Marketing Research 47, 199-214

Stern, P.C., Dietz, T., 1994. The Value Basis of Environmental Concern. Journal of Social Issues 50, 65-84

Stern, P.C., Dietz, T., Guagnano, G.A., 1998. A Brief Inventory of Values. Educational and Psychological Measurement 58, 984-1001

Stern, P.C., Kalof, L., Dietz, T., Guagnano, G.A., 1995. Values, Beliefs, and Proenvironmental Action: Attitude Formation Toward Emergent Attitude Objects. Journal of Applied Social Psychology 25, 1611-1636

Stock, J.R., Zinszer, P.H., 1987. The Industrial Purchase Decision for Professional Services. Journal of Business Research 15, 1-16

Svensson, G., Wood, G., Callaghan, M., 2010. A corporate model of sustainable business practices: An ethical perspective. Journal of World Business 45, 336-345

Tasalikis, J., Ortiz-Buonafina, M., 1994. Ethical Beliefs' Differences of Males and Females. Journal of Business Ethics 9, 509-517

Tate, W.L., Ellram, L.M., Kirchoff, J.F., 2010. Corporate Social Responsibility Reports: A Thematic Analysis Related to Supply Chain Management. Journal of Supply Chain Management 46, 19-44 
Treviño, L.K., Butterfield, K.D., McCabe, D.D., 1998. The Ethical Context in Organizations: Influences on Employee Attitudes and Behaviors. Business Ethics Quarterly 8, 447-476

Treviño, L.K., Hartman, L.P., Brown, M., 2000. Moral Person and Moral Manager: How Executives Develop a Reputation for Ethical Leadership. California Management Review 42, 128-142

Treviño, L.K., Weaver, G.R., Brown, M.E., 2015. It's Lovely at the Top: Hierarchical Levels, Identities, and Perceptions of Organizational Ethics. Business Ethics Quarterly 18, 233252

Treviño, L.K., Weaver, G.R., Gibson, D.G., Toffler, B.L., 1999. Managing Ethics and Legal Compliance: What Works and What Hurts. California Management Review 41, 131151

Tsoulfas, G.T., Pappis, C.P., 2006. Environmental principles applicable to supply chains design and operation. Journal of Cleaner Production 14, 1593-1602

Tudor, T.L., Barr, S.W., Gilg, A.W., 2007. Strategies for improving recycling behaviour within the Cornwall National Health Service (NHS) in the UK. Waste Management and Research 25, 510-516

Ulaga, W., Eggert, A., 2006. Value-Based Differentiation in Business Relationships: Gaining and Sustaining Key Supplier Status. Journal of Marketing 70, 119-136

van Tulder, R., van der Zwart, A., 2006. International Business-Society Management: Linking Corporate Responsibility and Globalisation. Routledge, London

van Weele, A.J., 2009. Purchasing and Supply Chain Management, 5th ed. Cengage Learning Emea

van Weele, A.J., van Raaij, E.M., 2014. The Future of Purchasing and Supply Management Research: About Relevance and Rigor. Journal of Supply Chain Management 50, 56-72

Velicer, W.F., DiClemente, C.C., Prochaska, J.O., Brandenburg, N., 1985. Decisional Balance Measure for Assessing and Predicting Smoking Status. Journal of Personality and Social Psychology 48, 1279-1289

Walker, H., Phillips, W., 2009. Sustainable procurement: emerging issues. International Journal of Procurement Management 2, 41-61

Walker, H., Seuring, S., Sarkis, J., Klassen, R., 2014. Sustainable operations management: recent trends and future directions. International Journal of Operations \& Production Management 34, null 
Walley, N., Whitehead, B., 1994. It's Not Easy Being Green. Harvard Business Review 72, 46-51

Weaver, G.R., Treviño, L.K., Cochran, P.L., 1999. Corporate Ethics Programs as Control Systems: Influences of Executive Commitment and Environmental Factors. Academy of Management Journal 42, 41-57

Weber, J., 1993. Exploring the Relationship Between Personal Values and Moral Reasoning. Human Relations 46, 435-463

Weiner, B., 1986. An Attributional Model of Motivation and Emotion. Springer-Verlag, New York

Werbach, A., 2009. Strategy for sustainability: a business manifesto. McGraw-Hill, New York

Wilken, R., Sichtmann, C., 2007. Estimating Willingness-to-Pay by Different Utility Functions - A Comparison of Individual and Cluster Solutions. ESCP Europe, Berlin

Williams, H.E., Medhurst, J., Drew, K., 1993. Corporate Strategies for Sustainable Future, In: Fischer, K., Schot, J. (Eds), Environmental Stragies for Industry: International Perspectives on Research Needs and Policy Implications. Island Press, Washington, D.C.

Williams, O.F., 2004. The UN Global Compact: The Challenge and the Promise. Business Ethics Quaterly 14, 755-774

Williamson, O.E., 1975. Markets and hierarchies: Analysis and antitrust implications: A study in the economics of internal organization. The Free Press, New York

Wu, Z., Pagell, M., 2011. Balancing priorities: Decision-making in sustainable supply chain management. Journal of Operations Management 29, 577-590

Yawar, S.A., Seuring, S., 2015. Management of Social Issues in Supply Chains: A Literature Review Exploring Social Issues, Actions and Performance Outcomes. Journal of Business Ethics 141, 621-643

Zadek, S., 2004. The Path to Corporate Responsibility. Harvard Business Review 82, 125-132

Zhu, Q., Sarkis, J., Cordeiro, J.J., Lai, K.-H., 2008. Firm-level correlates of emergent green supply chain management practices in the Chinese context. Omega 36, 577-591

Zizzo, D.J., 2010. Experimenter demand effects in economic experiments. Experimental Economics 13, 75-98 


\section{Appendix}

\begin{tabular}{|c|c|c|c|}
\hline Driver group & Parameter & Items & Source \\
\hline \multirow{12}{*}{$\begin{array}{l}\text { Individual } \\
\text { Values }\end{array}$} & \multirow{3}{*}{ Altruistic values } & A world at peace, free of war and conflict & \multirow{12}{*}{$\begin{array}{l}\text { Fritzsche and Oz (2007), } \\
\text { Stern et al. (1998) }\end{array}$} \\
\hline & & $\begin{array}{l}\text { Social justice, correcting injustice, care for the } \\
\text { weak }\end{array}$ & \\
\hline & & $\begin{array}{l}\text { Protecting the environment and preserving the } \\
\text { nature. }\end{array}$ & \\
\hline & \multirow{3}{*}{$\begin{array}{l}\text { Traditional } \\
\text { (or Conservative) } \\
\text { values }\end{array}$} & Honoring parents and elders, showing respect & \\
\hline & & Family security, safety for loved ones & \\
\hline & & $\begin{array}{l}\text { Self-discipline, self-restraint, resistance to } \\
\text { temptation }\end{array}$ & \\
\hline & \multirow{3}{*}{$\begin{array}{l}\text { Self-Enhancement } \\
\text { (or Egoistic) values }\end{array}$} & Authority, the right to lead or command & \\
\hline & & $\begin{array}{l}\text { Influential, having an impact on people and } \\
\text { events }\end{array}$ & \\
\hline & & Wealth, material possessions, money & \\
\hline & \multirow{3}{*}{$\begin{array}{l}\text { Openness to change } \\
\text { values }\end{array}$} & $\begin{array}{l}\text { A varied life, filled with challenge, novelty, and } \\
\text { change }\end{array}$ & \\
\hline & & An exciting life, stimulating experiences & \\
\hline & & Curious, interested in everything, exploring & \\
\hline \multirow{16}{*}{$\begin{array}{l}\text { Ethical } \\
\text { Culture }\end{array}$} & \multirow{4}{*}{$\begin{array}{l}\text { Ethical Behavior of } \\
\text { Top Management }\end{array}$} & $\begin{array}{l}\text { Top Managers in our organization... } \\
\text {... regularly show that they care about ethics. }\end{array}$ & \multirow{16}{*}{$\begin{array}{l}\text { Treviño et al. (1998), } \\
\text { Weaver et al. (1999) }\end{array}$} \\
\hline & & ... guide decision-making in an ethical direction. & \\
\hline & & $\ldots$ are models of ethical behavior. & \\
\hline & & ... represent high ethical standards. & \\
\hline & \multirow{3}{*}{$\begin{array}{l}\text { Obedience to } \\
\text { authority }\end{array}$} & $\begin{array}{l}\text { Our organization demands obedience to } \\
\text { authority }\end{array}$ & \\
\hline & & $\begin{array}{l}\text { People in our organization are expected to do as } \\
\text { they are told }\end{array}$ & \\
\hline & & The boss is always right in our organization & \\
\hline & \multirow{5}{*}{ Incentives } & $\begin{array}{l}\text { Management in our organization disciplines } \\
\text { unethical behavior when it occurs. }\end{array}$ & \\
\hline & & $\begin{array}{l}\text { Penalties for unethical behavior are strictly } \\
\text { enforced in our organization }\end{array}$ & \\
\hline & & $\begin{array}{l}\text { Unethical behavior is punished in our } \\
\text { organization. }\end{array}$ & \\
\hline & & $\begin{array}{l}\text { People of integrity are rewarded in our } \\
\text { organization. }\end{array}$ & \\
\hline & & Ethical behavior is rewarded in our organization. & \\
\hline & \multirow{4}{*}{ Code of Conduct } & $\begin{array}{l}\text { Purchasing professionals in our organization are } \\
\text { required to acknowledge that they have read and } \\
\text { understood the code of conduct. }\end{array}$ & \\
\hline & & $\begin{array}{l}\text { Our organization has established procedures for } \\
\text { employees to ask questions about code of } \\
\text { conduct requirements. }\end{array}$ & \\
\hline & & $\begin{array}{l}\text { The code of conduct is widely distributed } \\
\text { throughout our organization. }\end{array}$ & \\
\hline & & $\begin{array}{l}\text { Purchasing professionals in our organization are } \\
\text { regularly required to assert that their actions are } \\
\text { in compliance with the code of conduct. }\end{array}$ & \\
\hline
\end{tabular}

